\title{
THERMAL DESORPTION METASTABLE ATOM BOMBARDMENT IONIZATION AEROSOL MASS SPECTROMETRY
}

by

\section{CARLY B. ROBINSON}

B.A. Michigan Technological University, 2007

A thesis submitted to the faculty of the Graduate School of the University of Colorado in partial fulfillment of the requirements for the degree of

Master of Science

Department of Chemistry \& Biochemistry 
The thesis entitled

Thermal Desorption Metastable Atom Bombardment Ionization Aerosol Mass Spectrometer written by Carly B. Robinson

has been approved for the Department of Chemistry and Biochemistry.

Dr. Jose-Luis Jimenez, committee chair

Dr. Joel Kimmel, committee member

Date

The final copy of this thesis has been examined by the signatories, and we find that both the content and the form meet acceptable presentation standards of the scholarly work in the above mentioned discipline. 
Robinson, Carly B. (M.S., Chemistry and Biochemistry)

Thermal Desorption Metastable Atom Bombardment Ionization Aerosol Mass Spectrometer Thesis directed by Associate Professor Jose-Luis Jimenez

A metastable atom bombardment (MAB) ionization source has been coupled to an existing thermal desorption aerosol mass spectrometer. The design allows real-time alternation between MAB and electron ionization (EI). A jet of metastable species produced in a DC discharge is directed at the ionization volume of the mass spectrometer, where Penning ionization is thought to be the dominant mechanism. Performance is characterized in experiments with oleic acid particles. By changing discharge gases between $\mathrm{N}_{2}, \mathrm{Kr}$, and $\mathrm{Ar}$, the excited state energy of the metastable species can be adjusted in the range $8.5-11.7 \mathrm{eV}$. For vaporization at $180^{\circ} \mathrm{C}$, all gases yield significantly less fragmentation than EI, which could improve results of factor analysis. Fragmentation increases with vaporization temperature, but generated fragments have higher average mass than those produced by EI. Analyte signal levels are $0.1 \%$ and $0.006 \%$ of equivalent analysis with EI when using $\mathrm{Ar}^{*}$ and $\mathrm{Kr}^{*}$, respectively. These sensitivities are not practical for ambient studies, but are sufficient for source measurements, as demonstrated with direct measurements of biomass burning emissions. The measured $\mathrm{Ar}^{*}$ flux of $3.6 \times 10^{13} \mathrm{sr}^{-1} \mathrm{~s}^{-1}$ is 30 times lower than the best literature values for similar metastable beam sources, suggesting that sensitivity can be increased by source design improvements. 


\section{CONTENTS}

\section{CHAPTER}

I. THESIS INTRODUCTION

II. SUBMITTED ANALYTICAL CHEMISTRY PAPER

\section{Introduction}

Experimental Methods

Results and Discussion

Metastable Source Optimization

Stability of Metastable Beam

Fragmentation of Organic Compounds

Sensitivity of MAB-AMS

FLAME-3 Field Campaign

Conclusions

Acknowledgements

III. METASTABLE ATOM SOURCE DESIGNS, OPERATION, AND

\section{MAINTENANCE}

Faraday Cup Metastable Flux Detector

Metastable Beam Source Designs

Design 1 - Skimmer Anode Source

Design 2 - Off-axis Anode Source

Design 3 - Stainless Steel Aperture Anode Source

Design 4 - Microstructured Electrode Source 
Metastable Source Operation

Metastable Source Maintenance

IV. FUTURE RESEARCH

\section{REFERENCES}




\section{Tables}

1. Table of experiments performed with Design 1

2. Summary of the source Designs 1-4 and their achieved metastable fluxes

\section{Figures}

1. Schematic of the HR-ToF-AMS and of the coupling of the MAB source

2. Schematic of the metastable beam source coupled to the AMS

3. Metastable beam source design

4. Comparison of the background mass spectra varying deflection fields

5. Effect of the discharge current on total signal

6. Effect of the reagent gas pressure on AMS signals

7. Effect of metastable argon flux and argon discharge reagent gas pressure over time

8. Effect of AMS vaporizer temperature on the mass spectra

9. Difference mass spectra varying reagent discharge gases

10. Comparison of the M(Ar)B and EI instruments for multiple burns

11. Difference mass spectra of lodgepole pine smoke

12. Expanded difference mass spectra of lodgepole pine smoke 
13. Schematic of metastable flux detector

14. Schematic of Design 1

15. Schematic of the BN and LAVA nozzle

16. Schematic of Design 2

17. Schematic of Design 3

18. Schematic of Design 4 


\section{CHAPTER I}

\section{THESIS INTRODUCTION}

This thesis is comprised of 4 chapters. The first, this Thesis Introduction will explain how the thesis is structured and where information is included within the thesis. Chapter II is a paper submitted to Analytical Chemistry. The paper explains the optimization of the metastable source which was deemed the most successful design. It also discusses part of the first field campaign, FLAME-3, that the Metastable Atom Bombardment Aerosol Mass Spectrometer (MAB-AMS) was implemented in. Chapter III discussed the design and testing of four source designs. It also lays out a procedure for source operation and maintenance. Chapter IV discusses the future research that could follow on the results presented here. 


\section{CHAPTER II}

\section{SUBMITTED ANALYTICAL CHEMISTRY PAPER}

\section{Introduction}

Aerosols have important effects on regional and global climate, visibility, and human health. At present aerosols are considered by the Intergovernmental Panel on Climate Change as the most uncertain component in the radiative forcing of climate. ${ }^{1}$ Atmospheric aerosols are mixtures of organic and inorganic matter. The inorganic fraction is better understood, due to the smaller number of species, fewer sources, and simpler chemistry. Organic aerosols (OA), on the other hand, are complex mixtures of a wide variety of species with both natural and anthropogenic sources. Thorough chemical characterization of OA remains a significant challenge, and the sources and processing of OA are poorly known. This leads to inaccuracies in predictions of future climate forcing and requires new approaches for the analysis of OA. ${ }^{2}$

A number of techniques can quantify and characterize OA, but inevitably each technique has limitations. Thermal-optical instruments can quantify total organic carbon, ${ }^{3}$ while total watersoluble organic carbon can be quantified via capture into a liquid and online analysis. ${ }^{4}$ However both techniques are limited by their lack of chemical resolution, as they cannot identify subtypes of OA. Ideally OA could be characterized at a molecular level, but due to the extreme range of physical and chemical properties of OA species, only a small fraction of the mass of ambient OA has been compositionally resolved. ${ }^{2}, 5$ Several approaches attempt to characterize the composition of the total bulk OA, although at the expense of molecular information. These include FTIR, ${ }^{6}$ NMR, ${ }^{7}$ and online aerosol mass spectrometers, such as the Aerodyne Aerosol Mass Spectrometer (AMS) used in this work. ${ }^{8}$ The AMS flash vaporizes particles and ionizes 
the gaseous plume with electron ionization (EI). Recorded MS signals are quantitatively apportioned to total OA and non-refractory inorganic species. Factor analysis of AMS data allows the identification of several OA components which provide useful information about OA sources and processing. ${ }^{8}$ But, the high degree of molecular fragmentation generated by EI limits the information that can be extracted about molecular composition as well as source identification.

Better resolution of different sources of $\mathrm{OA}$ and classes of compounds comprising $\mathrm{OA}$ is highly desirable. Softer ionization techniques reduce or eliminate molecular fragmentation by imparting much less energy than EI during the ionization process. Vacuum ultraviolet (VUV) photoionization, ${ }^{9}$ chemical ionization, ${ }^{10-13}$ and low energy electron capture ionization ${ }^{14}$ have all been recently applied to OA analysis in the laboratory. Even for a softer ionization source the mass spectrum of ambient $\mathrm{OA}$ are extremely complex. Thus, for a direct analysis instrument like the AMS the main advantage of the more distinct mass spectra would be identification of additional chemical classes of atmospheric OA via factor analysis methods. ${ }^{15}$ The AMS represents a well-developed platform for atmospheric aerosol analysis, ${ }^{8}$ and thus the implementation of a soft-ionization source is simplified. A previous effort coupled a VUV lamp to the thermal desorption AMS platform. ${ }^{16}$ The VUV-AMS showed much reduced fragmentation compared to EI, but the sensitivity was $0.02 \%$ of EI. Currently a significantly more intense VUV lamp is not available that would allow for increased sensitivity.

This work develops and characterizes hardware for analysis of the AMS-vaporized aerosols by Penning ionization and mass spectrometry. The mechanism of Penning ionization imparts analyte molecules with energies near those imparted by VUV photoionization, and, to a first approximation, one could expect mass spectra generated by the two methods to be qualitatively 
similar. Penning ionization involves reaction of an analyte molecule (BC) with an excited-state, metastable molecule or atom $\left(\mathrm{A}^{*}\right) \cdot{ }^{17,18}$ If the ionization potential of the analyte is lower than the internal energy of the metastable species, an electron from the analyte molecule may transfer to a low-lying state of the metastable species forming an analyte cation and causing the loss of the excited electron from the metastable species.

$$
A *+B C \rightarrow A+B C^{+\cdot}+e-
$$

For cases where the internal energy of the metastable species is significantly greater than the ionization potential of the analyte, the generated cation may fragment:

$$
B C^{+\cdot} \rightarrow B^{+}+C
$$

Metastable species are commonly formed via controlled gas discharges. For cases where the discharge medium is a pure gas, one can theoretically tailor conditions to yield ionization with minimal fragmentation ${ }^{19}$ and/or to ionize only select classes of molecules. In this work we use gases with excited state energies between $8.45 \mathrm{eV}\left(\mathrm{N}_{2}{ }^{*}\right)^{20,21}$ and $11.72 \mathrm{eV}\left(\mathrm{Ar}^{*}\right),{ }^{22}$ which are well suited for the typical ionization energies of organic molecules $(9-11 \mathrm{eV}) .^{23}$

Current literature includes reports of many new atmospheric pressure ionization schemes that rely on the controlled production of metastable species. In some cases, analyte molecules are ionized directly by Penning ionization, ${ }^{24,} 25$ while other mechanisms involve the Penning ionization of a reagent gas and subsequent ionization of the analyte by chemical ionization mechanisms. ${ }^{26,27}$ This work targets the analysis of aerosols vaporized in the ionization volume of the AMS, which must be maintained under high vacuum. In 1993, Faubert et al..$^{22}$ demonstrated a new concept for Penning ionization at low pressure, which they termed metastable atom bombardment $(\mathrm{MAB})$ ionization. The design was based on the metastable beam sources of Fahey $^{28}$ and Searcy, ${ }^{29}$ where a low voltage (300 -1000 V) corona discharge is maintained 
between a sharpened needle and a skimmer electrode separated by a sonic nozzle. The sharpened electrode resides in a chamber containing a pure gas at 10-100 mbar and the skimmer electrode resides in an independently pumped stage. Expansion through the nozzle creates a jet containing metastable species, neutral, and charged species. The core of the jet passes through the skimmer, and into the low pressure ionization volume of the mass spectrometer. By using electric fields ${ }^{30}$ to remove charged species, the MAB ionization source created an ionization environment that was less complex than standard glow discharge methods in which the analyte is introduced into the discharge region. In this first application of the metastable beam source to mass spectrometry, Faubert et al. demonstrated the ability to tune ionization energy and the degree of fragmentation by changing the discharge gas ( $\mathrm{He}, \mathrm{Ne}, \mathrm{Ar}$, and $\mathrm{Kr}$ ) and they reported sensitivities for organic molecules that were approximately $20 \%$ of EI. Little has been published on the use of MAB ionization since that time. Most recently Le Clot et al. have coupled a MAB source to an FTICR mass spectrometer and achieved reported sensitivities comparable to $\mathrm{EI}^{31}{ }^{1}$ and a metastable beam source has recently been used for $\mathrm{Ar}^{*}$ induced fragmentation of peptide ions in a linear ion trap. ${ }^{32}$

In this work we have coupled a metastable beam source with an AMS to provide an instrument, termed the MAB-AMS, which measures the mass spectra of aerosol organic species with much reduced molecular fragmentation. The design of the implemented source is presented, key operating parameters are characterized, and the sensitivity and degree of fragmentation of the MAB-AMS are compared with those of the EI-AMS and of a previouslypublished VUV-AMS coupling. ${ }^{16}$ 


\section{Experimental Methods}

The AMS hardware and its application were detailed in a recent review, ${ }^{8}$ and the time-of-flight AMS is shown in Figure 1. Briefly, ambient particles are sampled directly from atmospheric pressure into the vacuum system of the AMS via an aerodynamic lens, ${ }^{33}$ which focuses particles into a tight beam. The beam traverses a high vacuum particle flight chamber. A rotating mechanical chopper at the beginning of the particle time-of-flight region can modulate the beam for size-resolved measurements (PToF mode). Alternatively, this chopper is alternated between discrete beam transmitting and non-transmitting positions for background-subtracted ensemble measurements (MS mode). At the end of the particle drift region, particles impact a heated surface (typically $600^{\circ} \mathrm{C}$ ) which leads to vaporization of non-refractory species. In the standard implementation, ${ }^{8}$ the resultant plume of vapor is analyzed by electron ionization (EI) mass spectrometry. Typically the filament used to create the electrons for EI has an emission current of 2.0mA. The AMS (Aerodyne Research, Billerica, MA) is available with three different mass spectrometers: a quadrupole mass spectrometer $^{34}$ (QMG 422, Balzers, Furstentum, Liechtenstein), a compact, high-sensitivity TOF mass spectrometer ${ }^{35}$ (CTOF, Tofwerk AG, Thun, Switzerland), or a high-resolution TOFMS $^{36}$ (HTOF, Tofwerk). This work used the HTOF-based instrument, called the HR-ToF-AMS,${ }^{36}$ but the MAB source design is not specific to this platform. 


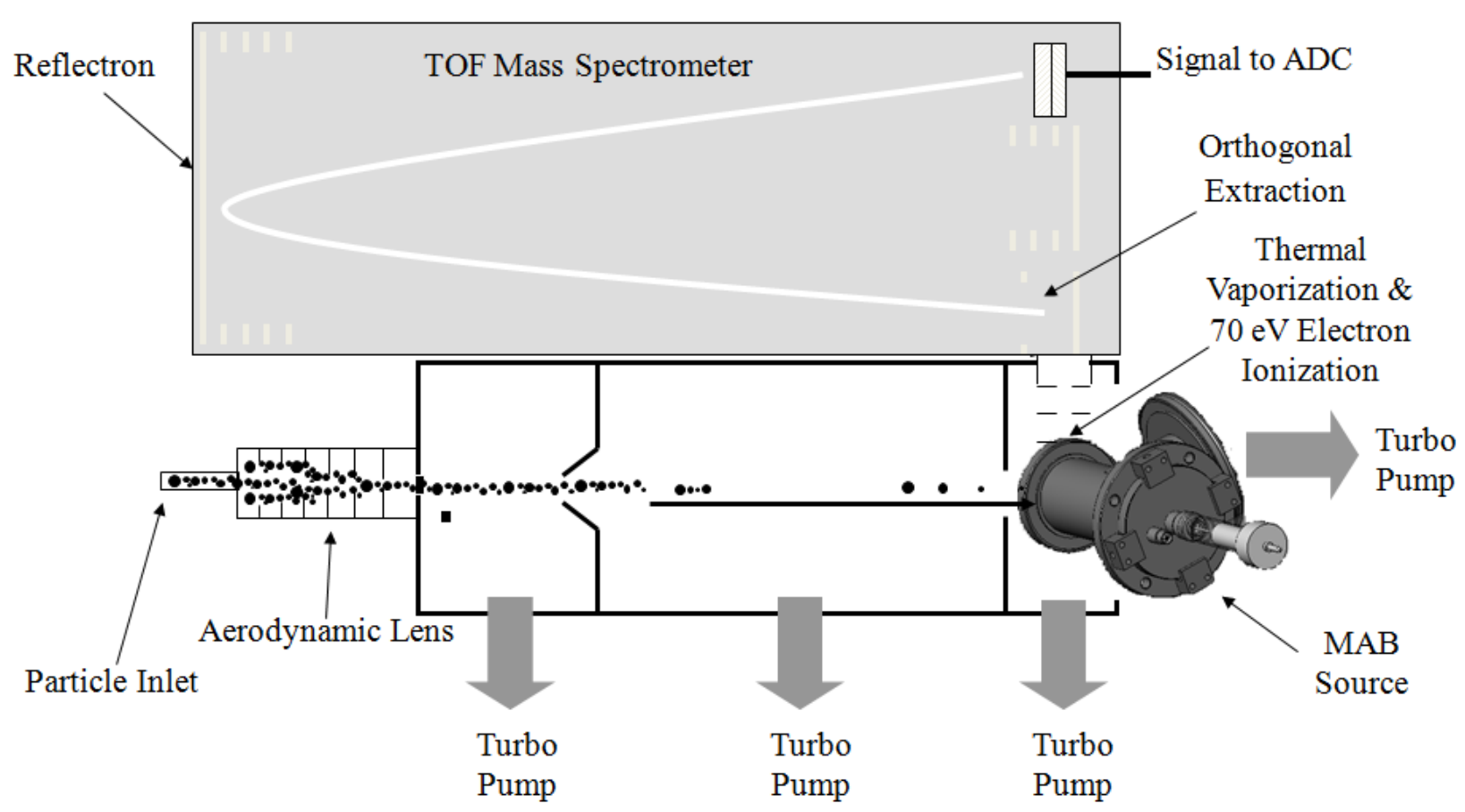

Figure 1. Schematic of the HR-ToF-AMS and of the coupling of the MAB source.

A schematic representation of the metastable beam source and the ionization region of the AMS is shown in Figure 2. The standard AMS has two EI filaments mounted on opposite sides of the ionization chamber. Here, one filament has been removed, and the metastable beam enters the ionization chamber through a $5 \mathrm{~mm}$ diameter hole in the ionization chamber at the position of the removed filament. The self-contained beam source is housed in a stainless-steel vacuum chamber (mechanical drawing available in Fig. 3), which attaches to the AMS vacuum system at an ISO-63 port immediately adjacent to the EI-vaporizer assembly. The beam-exit end of the source chamber extends into the AMS ionization chamber on an axis exactly opposite the remaining EI filament, to the point where the exit aperture of the source is in near contact with the ionization chamber assembly. Metastable species enter the ionization volume a few millimeters from the vaporizer surface. EI is kept inactive during MAB operation. The sensitivity of EI analysis is not significantly affected by the installation of the MAB source. 


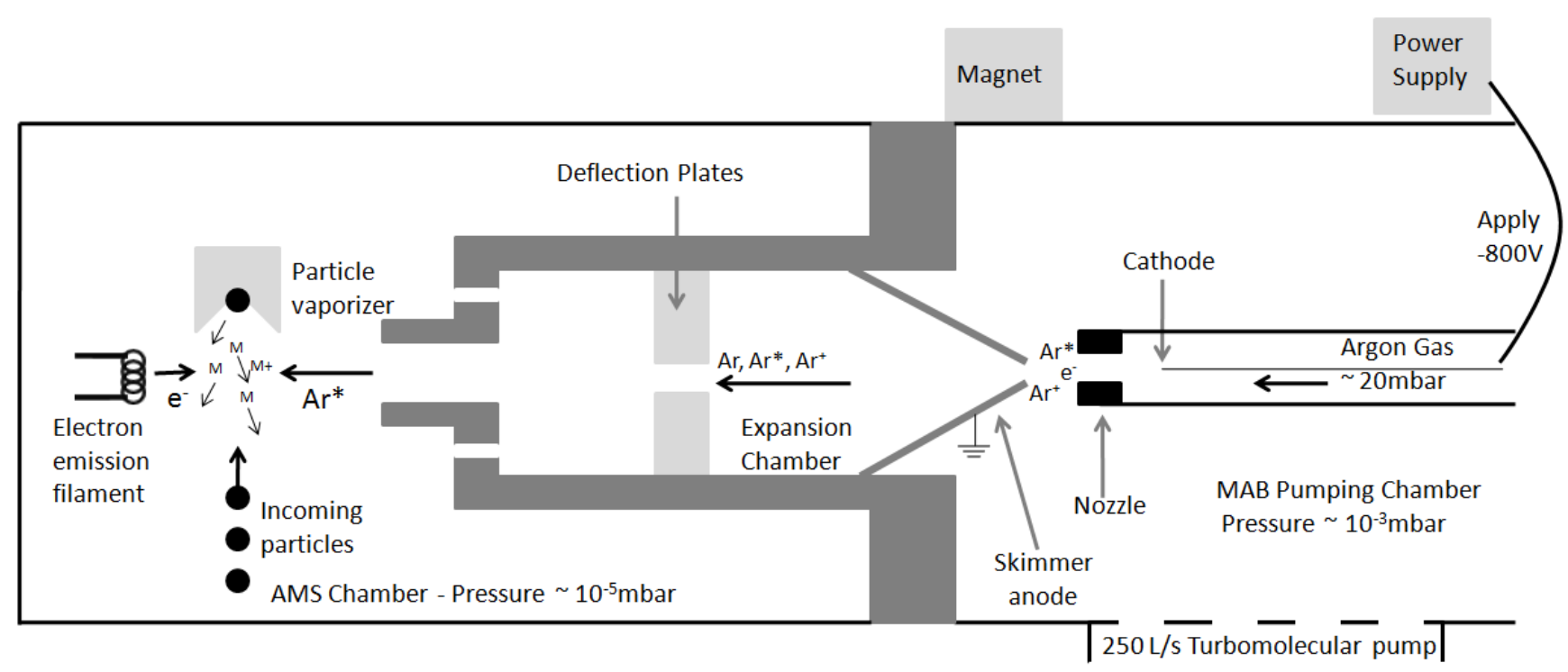

Figure 2. Schematic of the metastable beam source coupled to the AMS ionization region.

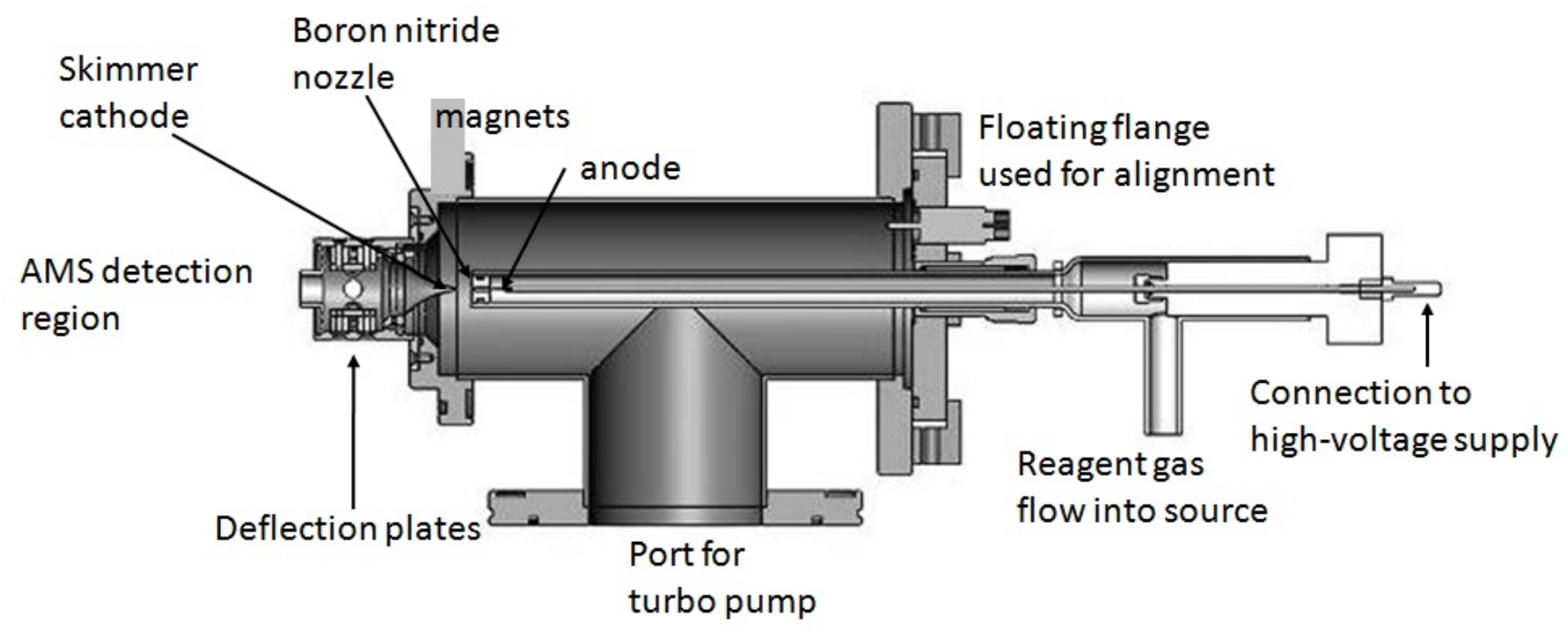

Figure 3. Metastable beam source design.

The principles of the metastable beam source were described in the introduction, and the employed design follows the work of Fahey, ${ }^{28}$ with minor modifications detailed here. The 
discharge is maintained between a sharp, $1 \mathrm{~mm}$ diameter tungsten cathode and a grounded stainless steel skimmer anode. The cathode is housed in a glass tube, referred to as the cathode chamber, having a $330 \mu \mathrm{m}$ diameter boron nitride nozzle at its exit. The pressure of the cathode chamber (typically 20 mbar) is monitored with a capacitance manometer (MKS Baratron, Andover, MA) and regulated by adjusting the flow of the discharge gas (argon, krypton, and nitrogen, each 99.9997\%, research grade, Airgas, Boulder, CO) into the chamber. The glass cathode chamber extends into the stainless steel source chamber through an Ultra-Torr (Swagelok, http://www.swagelok.com) 0.5 inch fitting on the front flange. This flange is moveable in the $\mathrm{X}-\mathrm{Y}$ plane and its position can be adjusted during operation to ensure optimum $\mathrm{X}$ and $\mathrm{Y}$ alignment of the nozzle and the skimmer aperture. ${ }^{37}$ The lateral distances ( $\mathrm{Z}$ axis) between the cathode tip and the nozzle and nozzle and the skimmer are also adjustable, although only when the system is not under vacuum. The region between the nozzle and the skimmer anode is pumped by a $250 \mathrm{Ls}^{-1}$ turbomolecular pump (V301, Varian Inc, Lake Forest, CA); pressure is not monitored but is estimated to be near $10^{-3}$ mbar. To initiate the discharge a voltage of approximately $-5000 \mathrm{~V}$ is applied to the cathode using a high voltage DC power supply in current-controlled mode (Series FC, Glassman, High Bridge, New Jersey). After the discharge is struck, the voltage drops to approximately $-800 \mathrm{~V}$ (depending on conditions) and a constant current is maintained. Discharges generated by this method have been reported to have metastable atom fluxes up to $10^{14}$ atoms $\mathrm{sr}^{-1} \mathrm{~s}^{-1}$ for $\operatorname{argon}^{28}$ and $10^{15}$ atoms $\mathrm{sr}^{-1} \mathrm{~s}^{-1}$ helium ${ }^{22}$ and to be stable $\left(<5 \%\right.$ variation in current) for durations in excess of one week. ${ }^{38}$

The core of the expansion jet created by the nozzle passes through the $1 \mathrm{~mm}$ aperture of the stainless steel skimmer anode, and enters the expansion chamber which contains two 16 x $16 \mathrm{~mm}$ deflection plates separated by $13.5 \mathrm{~mm}$. As indicated in Fig. 2, this expansion chamber extends 
into the AMS vacuum chamber. The housing of the expansion chamber is perforated, so that its volume is pumped by the AMS vacuum system, and the pressure is assumed to be equal to that of the AMS ionization region $\left(10^{-5}\right.$ to $10^{-6}$ mbar $)$. A magnet is mounted to the outside of stainless steel beam source chamber, just above the expansion chamber, producing a magnetic field of $\sim 0.02 \mathrm{~T}$ at the beam axis. The magnet is used in combination with the deflection plates (typically $100 \mathrm{~V}$ difference) to deflect charged species (e.g., $\mathrm{Ar}^{+}$and electrons) off the axis of the ionization chamber. Within the ionization chamber, metastable species react with gas-phase molecules from the vaporized aerosols, producing ions which are then analyzed by the mass spectrometer.

The source allows real time alternation between MAB ionization and EI. For long timescale alternation, the discharge and EI filament can simply be turned on and off. For more rapid alternation, both the discharge and the filament remain on. EI operation is toggled on and off by switching the electron acceleration energy between $70 \mathrm{eV}$ (on) and $0 \mathrm{eV}$ (off). For time periods where the electron energy is $0 \mathrm{~V}$, mass spectra are equivalent to operation with only $\mathrm{MAB}$ ionization. For time periods where the electron energy is $70 \mathrm{eV}$, the EI mechanism dominates the observed signal and the MAB ionization is treated as effectively negligible. Background peaks associated with EI of the discharge gas are removed by subtraction.

Source performance was optimized by two methods: aerosol mass spectral measurements and direct measurement of metastable species flux. MS experiments allow characterization of the instrument's analytical capabilities. The flux measurements allow the assembled source to be directly compared to other published designs (MS and non-MS applications).

For MS-based characterization oleic acid, $\mathrm{C}_{18} \mathrm{H}_{34} \mathrm{O}_{2},(99.0 \%$ purity, Sigma Aldrich, St. Louis, MO) aerosols were created using a TSI constant output atomizer (St. Paul, MN, model 3076) and 
analyzed by the AMS using MAB ionization and EI. Aerosol concentrations were not calibrated. Instead, the sensitivity of MAB ionization relative to EI was used as a sensitivity metric.

For metastable species flux measurements, a Faraday cup detector ${ }^{39,40}$ was mounted in the position of the AMS vaporizer-ionization chamber assembly with the metastable species beam directed at a stainless steel plate located at the back end of the detector cup. Collisions of metastable species with the surface cause the release of electrons. The generated replenishing current is measured with a picoammeter (model 6487, Keithley, Cleveland, Ohio). ${ }^{41}$ Electrodes in front of the stainless steel plate serve to deflect incoming electrons and ions, and to draw released electrons from the surface. A metastable species flux is calculated using the recorded electron current and geometry of the source and detector system, and assuming a metastable species-to-electron conversion factor of $0.13 \pm 0.09 .^{42}$ The Faraday cup detector was built with a $5 \mathrm{~mm}$ entrance aperture mimicking the through hole in the ion chamber, such that the measured current can be assumed approximately equal to the effective current of metastable species entering the ionization volume.

Field data are presented from the FLAME-3 experiment (Fire Lab at Missoula Experiment, Phase 3), which focused on quantification of emissions from controlled biomass burns simulating wildfires, and was conducted at the United States Forest Service's Fire Science Laboratory in Missoula, Montana. ${ }^{43}$ An HR-ToF-AMS equipped with the MAB source was positioned on the second story of the Fire Lab, and sampled directly (using a 20m-long 3/8 inch OD copper inlet with a flow of $10 \mathrm{~L} \mathrm{~min}^{-1}$ ) from a large smoke stack through which smoke was directed. Data are presented from an experiment where different materials were burned for $\sim 5$ minutes each. 


\section{Results and Discussion}

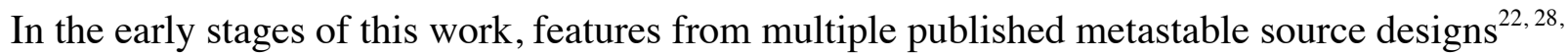
$29,37,38,40,44-47$ were explored to identify a design having high metastable flux, stability sufficient for field experiments (minimum of 12 hours of continuous data acquisition), and repeatable performance. Factors that were varied included: cathode shape, electrode geometry, cathode material, and nozzle material. Those results are not detailed here, but interested readers are pointed to the referenced works, which discuss these designs. The presented results refer to the source described in the experimental section.

Metastable Source Optimization. The gas jet exiting the discharge nozzle contains a mixture of neutral species, metastable species, ions, and electrons. Analyte molecules can be ionized by numerous mechanisms involving interactions with the charged species, most notably EI, which typically yields strong fragmentation. In order to simplify the ionization environment and allow Penning ionization to be the dominant mechanism, a combination of electric and magnetic fields is used to remove charged species from the beam directed into the AMS ionization volume. The first descriptions of MAB ionization and recent applications of beam source for metastableinduced fragmentation ${ }^{32}$ used only electrostatic deflection. In this work, strong deflection fields alone proved insufficient. Figure 4 shows a difference mass spectrum (particle beam transmitted data minus particle beam blocked data) of laboratory-generated oleic acid particles, collected using EI (fig 4a) and $\mathrm{Ar}^{*} \mathrm{MAB}(\mathrm{M}(\mathrm{Ar}) \mathrm{B})$ ionization with and without the applied magnetic and electric deflection fields (fig. 4b-e). When neither deflection plates nor a magnet are used (fig. 4b) the MAB-AMS spectrum has a similar degree of fragmentation compared to the EI-AMS spectrum with the majority of the total signal below $\mathrm{m} / \mathrm{z} 100$, suggesting that ionization is 
dominated by discharge electrons. When only the deflection plate voltage is applied (fig. 4c) the fraction of the signal from the parent plus dehydrated molecular ion $\left(F_{p}\right)$ doubles, and there is an increase in the relative intensity of fragments above $\mathrm{m} / \mathrm{z}$ 100. Simultaneously, deflection of charged species $\left(\mathrm{Ar}^{+}\right.$and/or $\left.\mathrm{e}^{-}\right)$leads to a 23 -fold reduction in total recorded ion current. Calculations suggest that the applied deflection voltages should be more than sufficient to deflect all of the $\mathrm{Ar}^{+}$and $\mathrm{e}^{-}$, and operation at substantially higher voltages (up to 10x) results in little change in the spectrum. But, when a magnetic field is applied alone (fig. 4d) or concurrent to the deflection plates (fig 4e), fragments below $\mathrm{m} / \mathrm{z} 50$ are nearly eliminated. It is clear that the magnets are more effectively removing electrons from the axis of the ionization volume, but the exact mechanism of removal is unknown. For instance, the magnets could be changing the nature of the discharge between the nozzle and skimmer, or the magnets could be removing electrons generated in processes downstream of the deflection plates (which could also explain the lack of efficiency of the deflection plates). Unless otherwise noted, both magnets and deflection plates were used for all data presented in the remainder of this paper. In future designs the deflection plates will not be incorporated into the design and only the magnet will be used. 


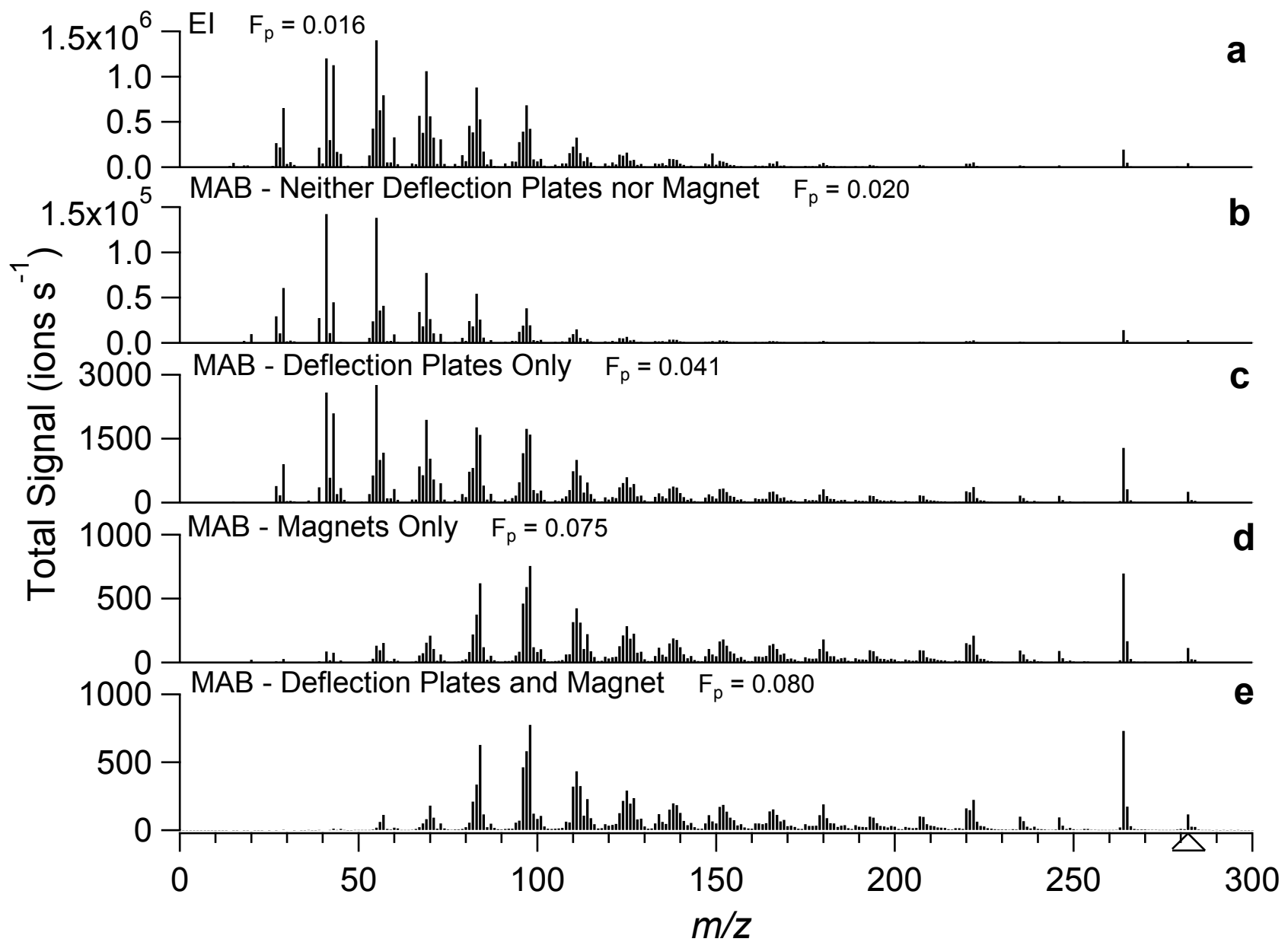

Figure 4. Comparison of the background subtracted mass spectra of pure oleic acid aerosol standards acquired with a vaporizer temperature of $200^{\circ} \mathrm{C}$ ionized by (a) EI (b) MAB without deflection or a magnet (c) MAB with only deflection plates, (d) MAB with only a magnet, and (e) MAB with a magnet and deflection plates in the experimental setup. $F_{p}$ is the ratio of the signal from the parent plus dehydrated oleic acid ions to the total signal.

The primary tunable parameters of the MAB ionization source are discharge current and discharge gas pressure. Metastable beam sources of similar design are typically run near 10 $\mathrm{mA} .^{22,37}$ For our source, a current greater than $6 \mathrm{~mA}$ is required to maintain a stable discharge. Above a current of $16 \mathrm{~mA}$ oxidized material starts to form on the tip of the tungsten cathode, leading to rapid degradation and discharge failure. The metastable flux is approximately $30 \%$ 
greater at $16 \mathrm{~mA}$ than at $8 \mathrm{~mA}$, and the observed $\mathrm{MS}$ ion current is directly proportional to this flux (fig. 5). Typical experiments are run at $12 \mathrm{~mA}$ to ensure longer term stability.

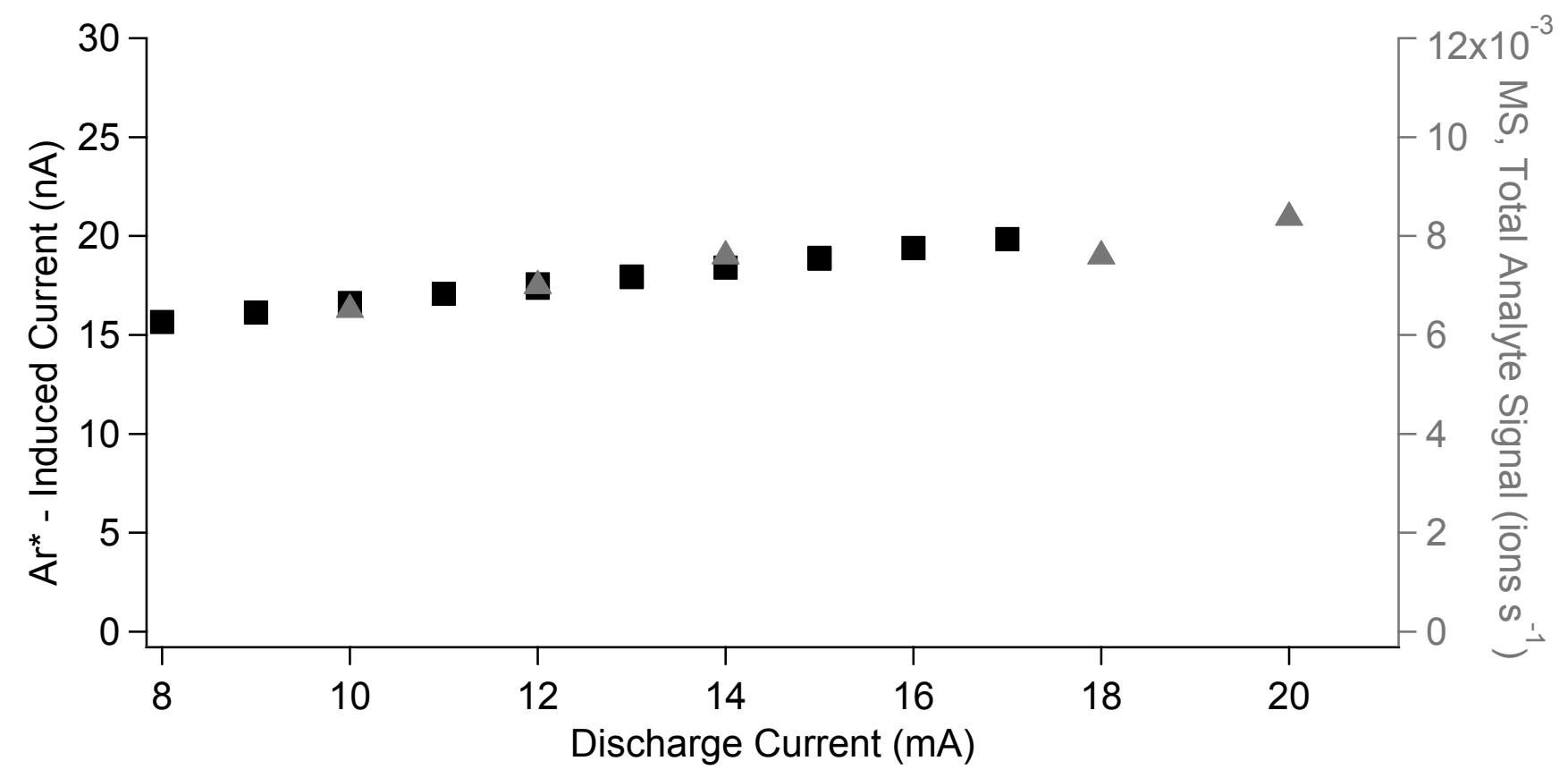

Figure 5. Effect of the discharge current on observed metastable species flux and on total MS signal when sampling a constant concentration of pure oleic acid aerosol standards. The left, black axis is the observed $\mathrm{Ar}^{*}$ induced current at the Faraday detector. The right, gray axis is the total MS signal.

Cathode chamber pressure varies greatly for $\mathrm{Ar}^{*}$ beam sources $\left(40^{22}\right.$ to $\left.400 \mathrm{mbar}^{45}\right)$, depending on design geometry and pumping. For our source, a discharge cannot be maintained below 13 mbar and above 65 mbar the gas load becomes too high for the vacuum system. The effect of cathode chamber pressure in this range was characterized using an argon discharge for the ionization of oleic acid particles. Figure 6 shows the total signal at $m / z, 40,43,264$, and 282 as a function of cathode chamber pressure. These peaks correspond to $\mathrm{Ar}^{+}$, an oleic acid fragment indicative of EI, dehydrated oleic acid, and the oleic acid parent ion, respectively. The EI indicator at $m / z 43$ displays no apparent pressure dependence. On the other hand, the parent and 
dehydrated parent peaks $(\mathrm{m} / \mathrm{z} 282$ and 264), which are presumed to originate by Penning ionization when electromagnetic deflection is enabled, both reach maximum intensity at $\sim 17$ mbar and then rapidly decrease in intensity. Metastable argon flux measurements show identical pressure dependence, reaching a maximum at 17 mbar and then decreasing with increased pressure, suggesting that this trend is due to the changes in metastable argon reaching the ionization volume. The observed reduction in metastable argon population is thought to be the result of collisional quenching. ${ }^{24}$

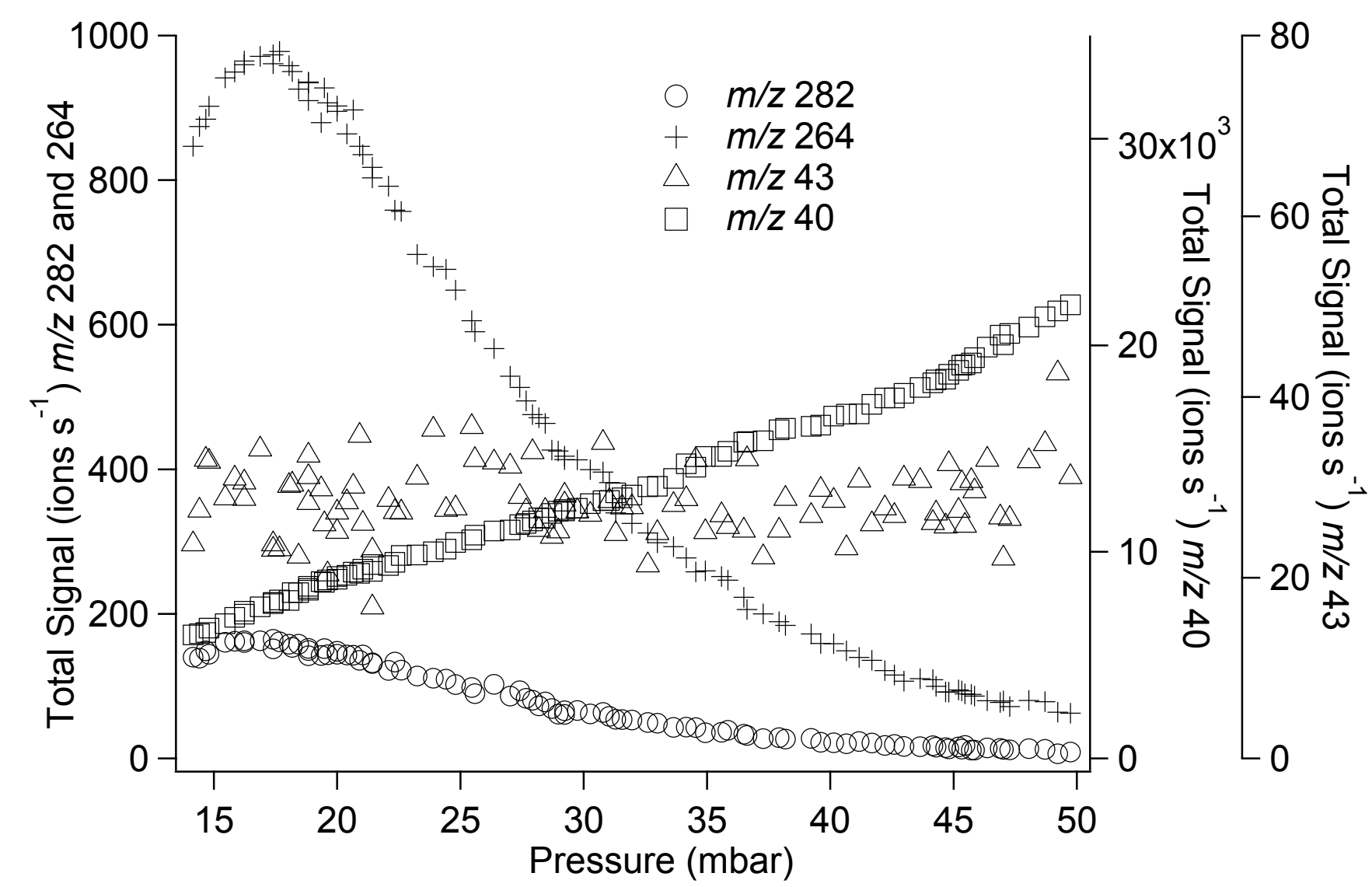

Figure 6. Effect of the discharge gas pressure on AMS signals while using a constant concentration of pure oleic acid aerosol standards. $\mathrm{m} / \mathrm{z}, 40$ corresponds to $\mathrm{Ar}^{+}$, while $\mathrm{m} / \mathrm{z}, 43$ peak is a marker for highly fragmented oleic acid molecules. $\mathrm{m} / \mathrm{z} 264$ and 282 correspond to dehydrated oleic acid and the oleic acid parent ion, respectively. 
Stability of the Discharge. Atmospheric field studies, which have typical durations of 1 month, ${ }^{48,49}$ demand an ionization source that is stable and that yields reproducible performance day-to-day. Ar $^{*}$ metastable flux was recorded for 3 weeks of continuous operation, with no adjustment to any source variables. The discharge demonstrated good stability with an average flux of $3.6 \times 10^{13} \mathrm{sr}^{-1} \mathrm{~s}^{-1}$ and $6 \%$ standard deviation, with a range of deviation of $\pm 13 \%$ of the average value within this period (data shown in figure 7). Some fluctuations in flux correlated strongly with changes in cathode chamber pressure, which were possibly due to changes in laboratory temperature. During a separate experiment the ambient temperature at the AMS inlet was recorded and it was observed that changes in reagent gas pressure were correlated with temperature changes. Future work will implement automated pressure control to eliminate such fluctuations. 


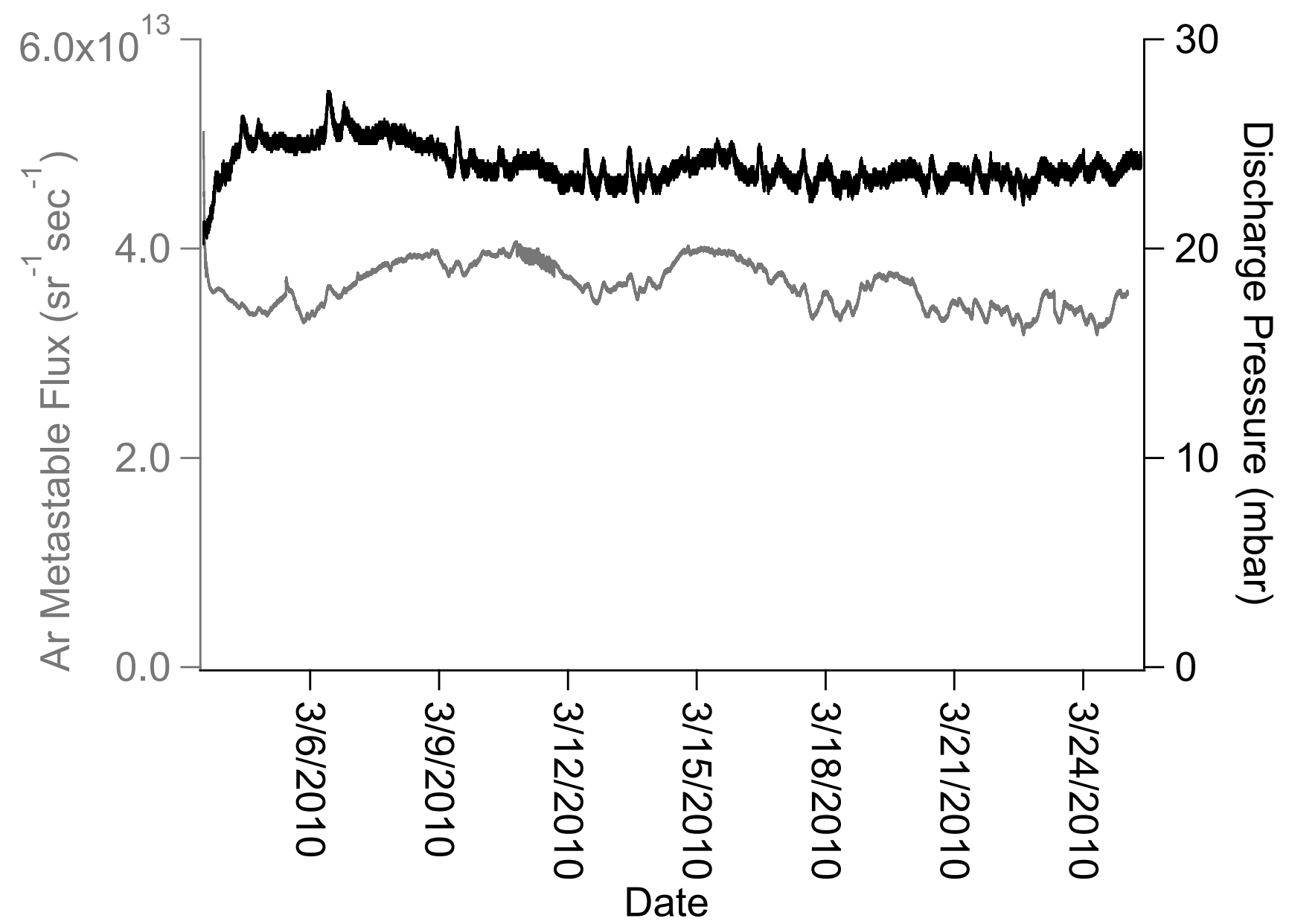

Figure 7. Metastable argon flux (gray, left-axis) and argon cathode chamber pressure (black, right-axis) over a period of 3 weeks of continuous operation.

Fragmentation of Organic Compounds. The MAB ionization source was coupled to the AMS with the specific aim of reducing fragmentation in mass spectra of OA. For more standard gas-phase analysis conditions (e.g., GC) with a MAB ionization source, fragmentation of analyte ions is driven by excess internal energy acquired in the Penning ionization electron transfer reaction. In the MAB-AMS, metastable species are interacting with analyte molecules generated by a hot vaporizer in high vacuum. These molecules may acquire substantial internal energy during vaporization, leading to molecular decomposition before ionization and/or enhanced fragmentation after ionization. For the EI-AMS, the vaporizer temperature is typically set to 
$600^{\circ} \mathrm{C}$ to ensure vaporization of all $\mathrm{OA}$ species and common inorganics. However, vaporizer temperatures as low as $180^{\circ} \mathrm{C}$ are sufficient to evaporate about $75 \%$ of ambient $\mathrm{OA}$ species..$^{50}$ The effects of vaporization temperature on observed M(Ar)B-AMS oleic acid mass spectra are presented in Fig 8. Fig. 8a shows the total ion signal recorded by the MAB-AMS as a function of temperature. For a fixed aerosol concentration, this reflects the efficiency of vaporization. Fig. 4a also shows $F_{p}$ (the ratio of $m / z 282+m / z, 264$ to the total ion signal) as a function of vaporizer temperature. While the total ion current increases by $25 \%, F_{p}$ drops by a factor of 4 across the range between 180 and $600^{\circ} \mathrm{C}$, demonstrating the improved "softness" of analysis with reduced temperature vaporization. Figures 8b-g display mass spectra of oleic acid aerosols for 3 temperatures acquired using $\mathrm{EI}(70 \mathrm{eV})$ and $\mathrm{M}(\mathrm{Ar}) \mathrm{B}$ ionization. The fragmentation patterns of EI mass spectra are similar at the 3 temperatures, with the fraction of the signal above $\mathrm{m} / \mathrm{z} 100$ increasing only from $10 \%$ to $20 \%$ over the entire temperature range, most of the signal remaining below $m / z, 100$, and $F_{p}$ being at least five times smaller than for $\mathrm{M}(\mathrm{Ar}) \mathrm{B}$ at the same temperature. The M(Ar)B spectra are more sensitive to vaporizer temperature; at $600^{\circ} \mathrm{C} 42 \%$ of the signal is above $\mathrm{m} / \mathrm{z} 100$, while at $180^{\circ} \mathrm{C} 70 \%$ of the signal is above $\mathrm{m} / \mathrm{z} 100$ and at $305^{\circ} \mathrm{C}$ the degree of fragmentation is in between those extremes. Even at $600^{\circ} \mathrm{C}$, the envelope of fragment ions is shifted to higher $\mathrm{m} / \mathrm{z}$ than for EI (note for instance the difference in mass spectra below $\mathrm{m} / \mathrm{z} 50$ ). Recognizing that optimum vaporization temperature and fragmentation vs. temperature will vary for the different components of heterogeneous OA sources, programmed vaporizer temperature ramping has been used in applications of the MAB-AMS. 

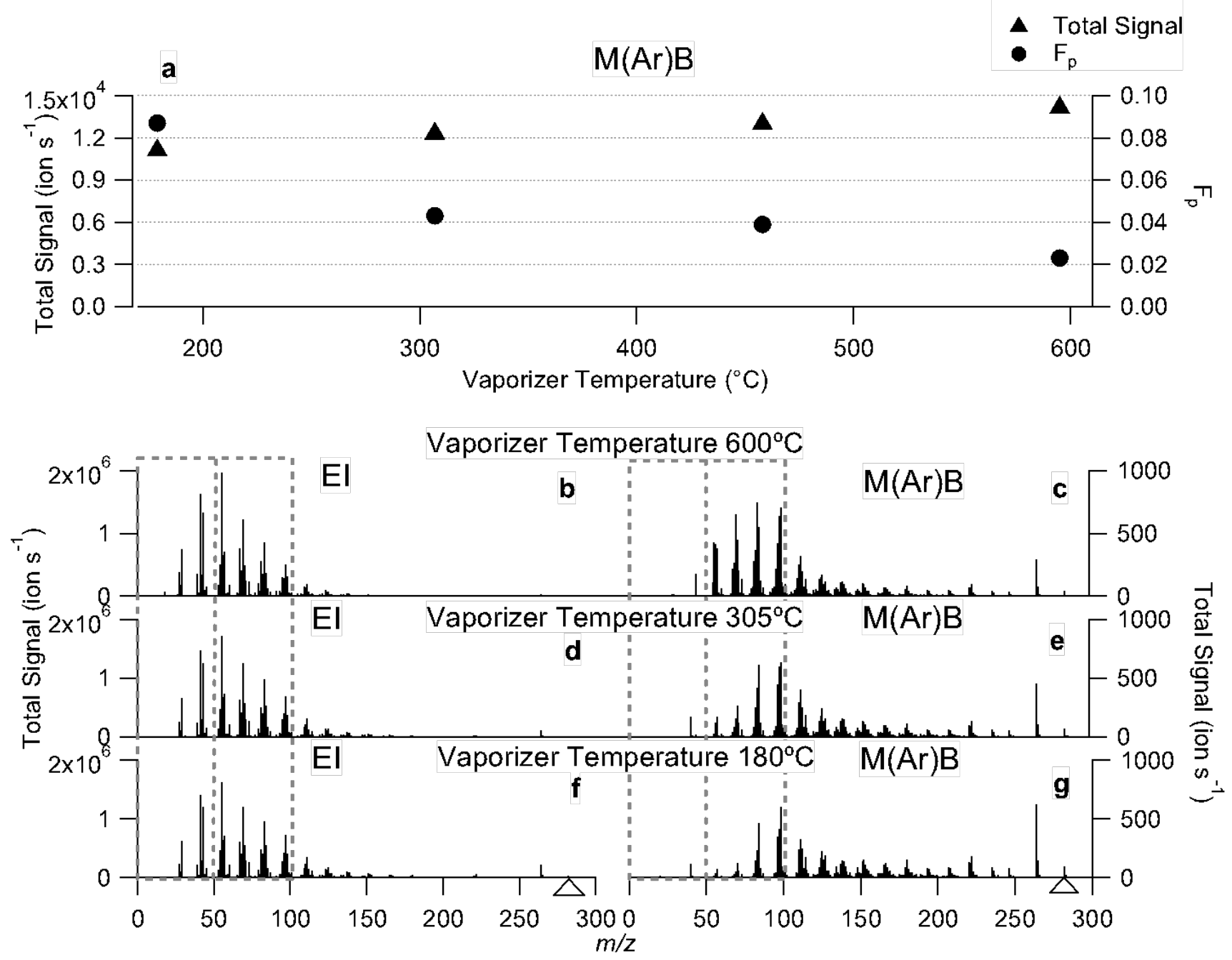

Figure 8. Effect of AMS vaporizer temperature on the mass spectra of pure oleic acid aerosol standards: (a) Normalized total ion signal and $\mathrm{F}_{\mathrm{p}}$ vs. $T_{\text {vap }}$. (b-e): Pure oleic acid difference mass spectra obtained using (b) EI with $T_{\text {vap }}=600^{\circ} \mathrm{C}$; (c) $\mathrm{M}(\mathrm{Ar}) \mathrm{B}$ with $T_{\text {vap }}=600^{\circ} \mathrm{C}$; (d) EI with $T_{\text {vap }}=305^{\circ} \mathrm{C}$; (e) $\mathrm{M}(\mathrm{Ar}) \mathrm{B}$ with $T_{\text {vap }}=305^{\circ} \mathrm{C}$; (f) EI with $T_{\text {vap }}=180^{\circ} \mathrm{C}$; (g) $\mathrm{M}(\mathrm{Ar}) \mathrm{B}$ with $T_{\text {vap }}=180^{\circ} \mathrm{C}$.

The energy of the Penning ionization reaction can be adjusted by changing the discharge gas. This tunability can potentially be exploited to achieve selective ionization or to affect the degree of molecular fragmentation. The MAB-AMS has been used with beams of $\mathrm{Ar}^{*}, \mathrm{Kr}^{*}$, and $\mathrm{N}_{2}{ }^{*}$ which have primary excited state energies of 11.73 and $11.55 \mathrm{eV}, 10.56$ and $9.92 \mathrm{eV}$, and 8.45 and $6.22 \mathrm{eV},{ }^{18}$ respectively. Figure 9 compares the mass spectra of oleic acid aerosols measured 
with the MAB-AMS using these different discharge gases and EI with a vaporizer temperature of $165 \pm 5^{\circ} \mathrm{C}$ (which is the lowest temperature that can be achieved with the ionizer operating at normal emission current and no control current applied to the vaporizer). $F_{p}$ values are reported for each mass spectrum. As expected, observed fragmentation decreases with metastable species excited state energy. The dominant state(s) of $\mathrm{N}_{2}{ }^{*}$ produced in this discharge are unknown, but the qualitative appearance of the spectra suggest that the effective energies are similar to that of $\mathrm{Kr}^{*}$. The total recorded ion signal is approximately equal for $\mathrm{Kr}^{*}$ and $\mathrm{N}_{2}{ }^{*}$, and is about $5 \%$ of that observed with Ar*. Sensitivity relative to EI is discussed below.

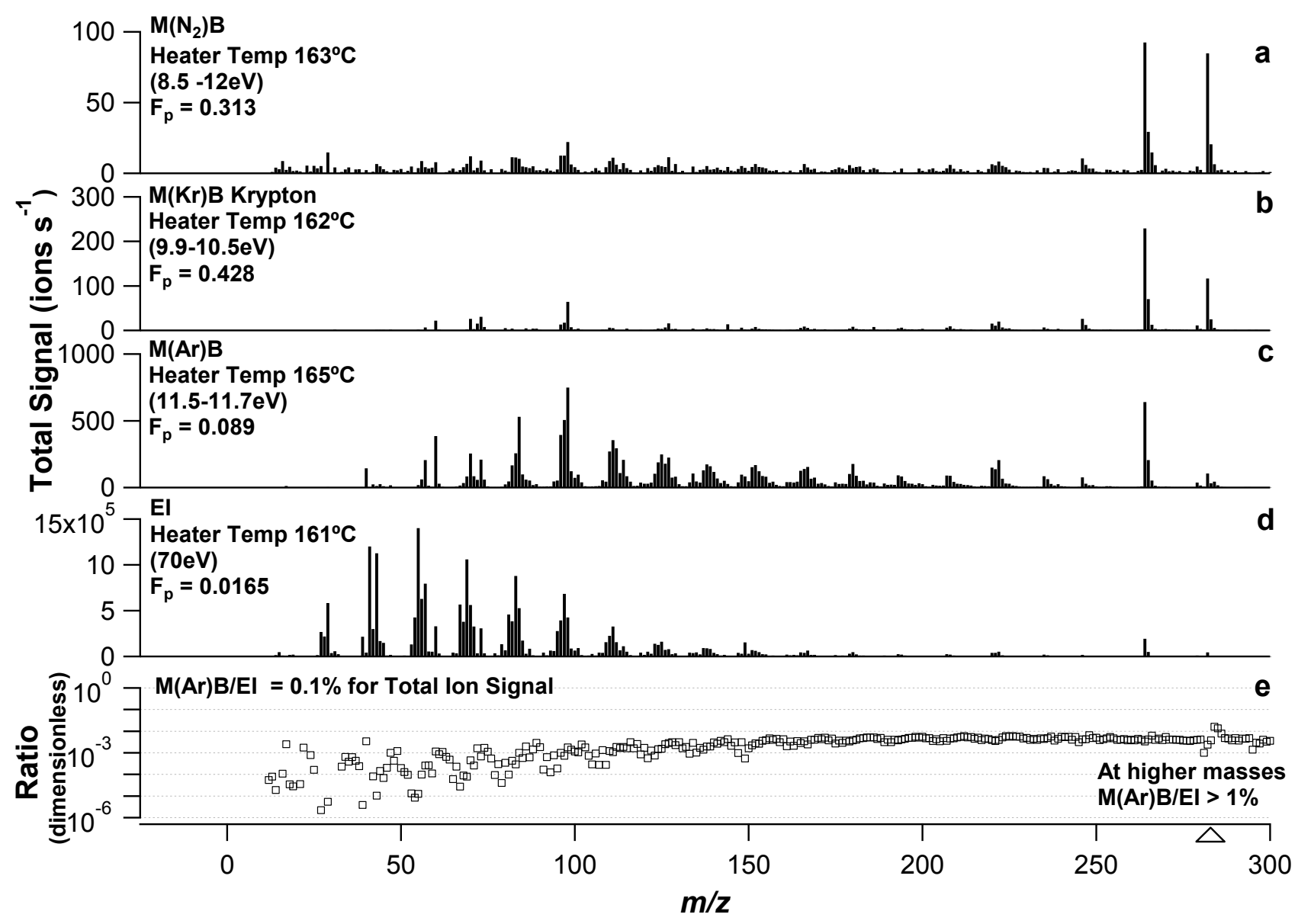

Figure 9. Difference mass spectra of pure oleic acid aerosol standards using ionization by: (a) $\mathrm{M}\left(\mathrm{N}_{2}\right) \mathrm{B}$; (b) $\mathrm{M}(\mathrm{Kr}) \mathrm{B}$; (c) M(Ar)B; (d) EI. (e) Ratio of the signals of M(Ar)B/EI for each $\mathrm{m} / z$. 
Northway et al. ${ }^{16}$ published $F_{p}$ values for oleic acid analysis with the VUV-AMS at several photon energies and vaporizer temperatures, using tunable synchrotron radiation. For $10.0 \mathrm{eV}$, which is a primary emission energy of the $\mathrm{Kr}$ lamp, $F_{p}$ was 0.45 at $200^{\circ} \mathrm{C}$ and 0.55 at $140^{\circ} \mathrm{C}$. This can be compared to the 0.31, 0.42, and 0.09 for $\mathrm{N}_{2}, \mathrm{Kr}$, and Ar discharges, respectively, each near $165^{\circ} \mathrm{C}$. Qualitatively, the VUV spectra obtained with the lamp, having dominant lines at 10.0 and $10.6 \mathrm{eV}$, appear very similar to the $\mathrm{M}(\mathrm{Kr}) \mathrm{B}-\mathrm{AMS}$ data.

Sensitivity of MAB-AMS. Figure 9e compares the recorded signal intensities for M(Ar)B and EI at each $m / z$ in the oleic acid mass spectra. At $m / z$ values greater than $150, \mathrm{M}(\mathrm{Ar}) \mathrm{B}$ signals are approximately $1 \%$ of EI, while the total ion current over all $\mathrm{m} / \mathrm{z}$ values is $0.1 \%$ of EI. This relative signal intensity is far below the $20 \%$ reported by Faubert. ${ }^{22}$ This discrepancy could be due to either differences in operating conditions of the EI sources, or in the intensities of the metastable beams reaching the ionization volumes. The operating conditions of the EI source were not described in that work, but a $\mathrm{He}^{*}$ flux of (1.2 to 1.5) $\mathrm{x} 10^{15} \mathrm{sr}^{-1} \mathrm{~s}^{-1}$ was reported. Literature values for other $\mathrm{Ar}^{*}$ beam sources range between $10^{12}$ and $10^{15} \mathrm{sr}^{-1} \mathrm{~s}^{-1} \cdot{ }^{28,38,45}$ These values can be compared to the flux of the MAB-AMS source, which is typically $3.6_{-1.5}^{+8.1} \times 10^{13} \mathrm{sr}^{-}$ ${ }^{1} \mathrm{~s}^{-1}$. The 30 times lower flux (uncertainty range 10-50) at the ionization volume of the MABAMS source compared with the best $\mathrm{Ar}^{*}$ literature source could reasonably explain most of the 2 orders of magnitude difference in relative $\mathrm{MAB} / \mathrm{EI}$ sensitivities, with the rest of the difference potentially due to differences in the EI sources in the two studies. The cause of the lower flux is unclear, but may be related to the differences in source geometry or pumping conditions between this source and the best performing sources. These parameters will be explored in future optimization of the MAB source.

The $\mathrm{M}(\mathrm{Ar}) \mathrm{B} / \mathrm{EI}$ ratio of $0.1 \%$ represents an improvement over the reported $0.02 \%$ which was reported for the VUV-AMS sytstem. ${ }^{16}$ And, importantly, it is expected that this sensitivity can be increased with improvements in the metastable beam source design. The detection limit for 
organic aerosols (OA) of the EI-AMS used in this work is approximately $0.1 \mu \mathrm{g} \mathrm{m}^{-3}$ (5 min averages). For a MAB/EI signal ratio of $0.1 \%$, the detection limit of the MAB-AMS can be estimated (proportionally to the square root of the signal) as $3.1 \mu \mathrm{g} \mathrm{m}^{-3}$, which is sufficient for sampling aerosol sources, such as biomass burning smoke, at typical concentrations of a few hundred $\mu \mathrm{g} \mathrm{m}^{-3}{ }^{43}$ However the current MAB-AMS sensitivity would not provide practical time resolution for sampling in polluted urban conditions, where ambient OA concentrations are in the range of 5 to $20 \mu \mathrm{g} \mathrm{m}^{-3} .51$

FLAME-3 Field Campaign. As a first field deployment, the MAB-AMS was run during the 1-month FLAME-3 campaign, which measured emissions of controlled biomass burns. Figure 10 compares $\mathrm{M}(\mathrm{Ar}) \mathrm{B}-\mathrm{AMS}$ signal to data from a separate EI-AMS that was sampling in parallel through a second inlet located at a different location on the exhaust stack. ${ }^{52}$ The time series shows total mass spectral signal across two burns. Features in the two traces are similar, suggesting that $\mathrm{Ar}^{*}$ are ionizing the major species in the burn emissions. The inset compares the total organic aerosol signal recorded by each instrument for a larger collection of burns. Burns are indicated by number, and each number is a different fuel. The ratio of the signals from the two instruments is constant within a factor of 3 . Given that slightly different smoke concentrations were sampled due to the different inlet locations, this suggests that MAB-AMS has near linear response to changes in OA concentration for the very diverse types of OA produced when burning different biomasses. ${ }^{43}, 52$ Mass spectra for lodgepole pine smoke (a complex mixture of organic molecules) analyzed with $\mathrm{EI}, \mathrm{M}(\mathrm{Ar}) \mathrm{B}, \mathrm{M}(\mathrm{Kr}) \mathrm{B}$, and $\mathrm{M}\left(\mathrm{N}_{2}\right) \mathrm{B}$ ionization are shown in figures 11 and 12. MAB spectra of smoke have enhanced signal at higher $\mathrm{m} / \mathrm{z}$ in comparison to the EI spectrum. In addition, molecular and marker ions become more 
distinctly resolved in MAB, even though they may be present at higher intensity for EI, due to the reduced contribution of fragment ions at neighboring $\mathrm{m} / \mathrm{z}$.

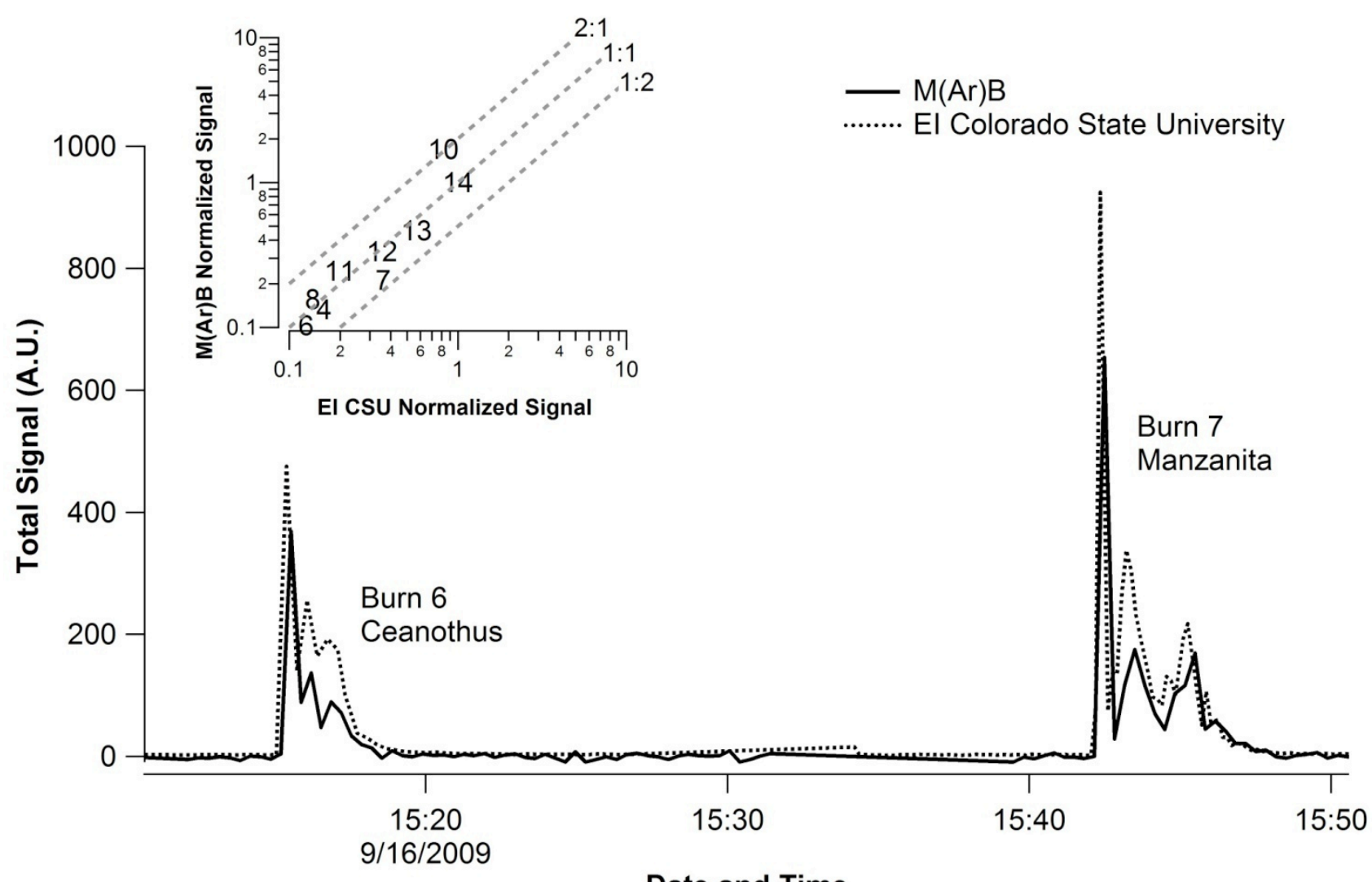

Date and Time

Figure 10. Comparison of the time series of total M(Ar)B and EI instrument OA signals for two burns. Inset: Scatter plot of the integrated signals from M(Ar)B and EI for nine biomass burns. Data have been normalized to the total ion signal of burn 14. Note that due to the use of two separate inlets, perfect correspondence of the concentration time series is not expected. 


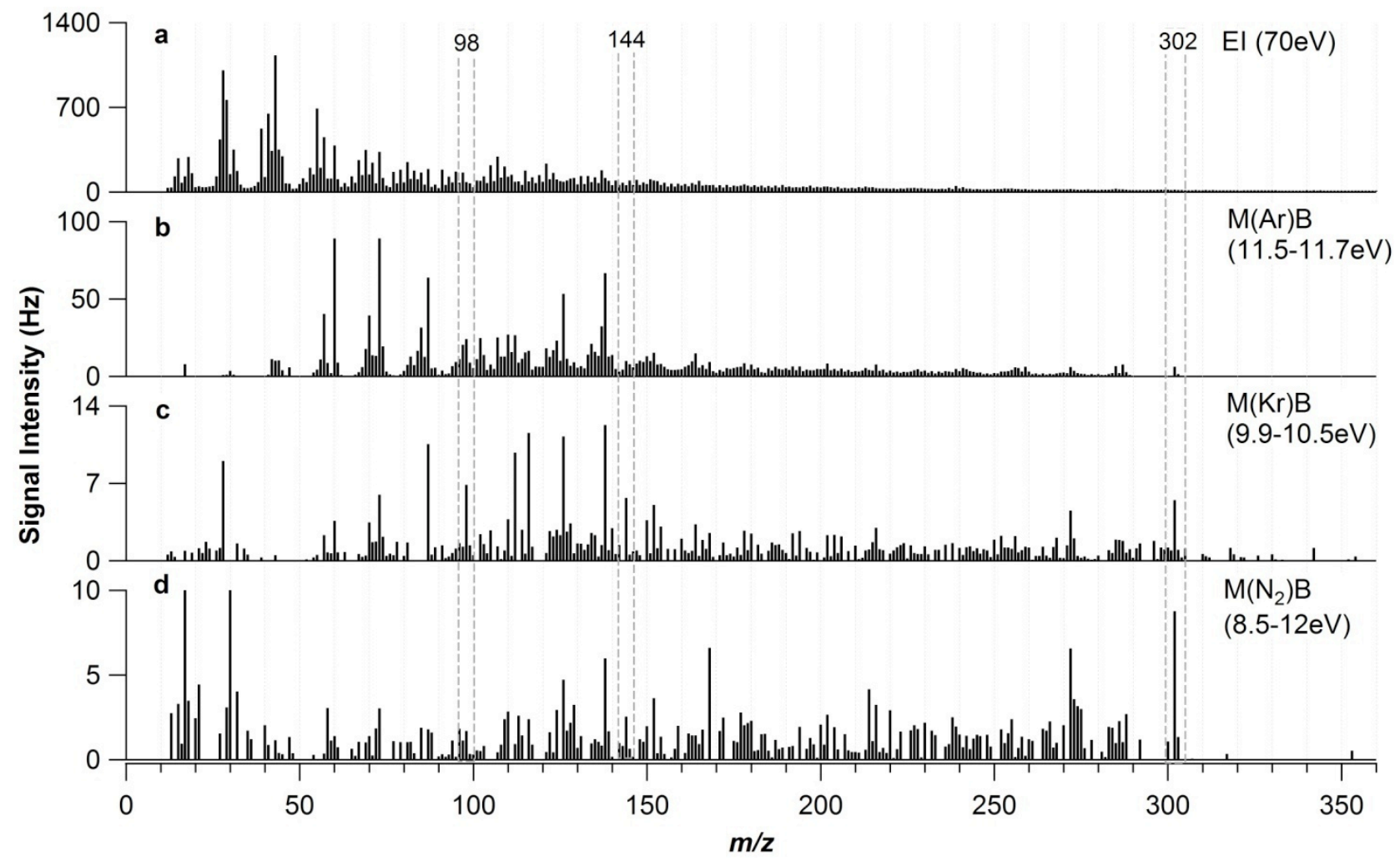

Figure 11. Background-subtracted mass spectra of Lodgepole Pine smoke using ionization by: (a)EI; (b) $\mathrm{M}(\mathrm{Ar}) \mathrm{B}$; (c) $\mathrm{M}(\mathrm{Kr}) \mathrm{B}$; (d) $\mathrm{M}\left(\mathrm{N}_{2}\right) \mathrm{B}$. Marker ions consistent with those generated by the biomass burning molecular tracers levoglucosan $(\mathrm{m} / \mathrm{z}, 98$ and 144$)$ and abietic acid $(\mathrm{m} / \mathrm{z} 302)$ are highlighted. MAB spectra of smoke have enhanced signal at higher $\mathrm{m} / \mathrm{z}$ in comparison to the EI spectrum. 


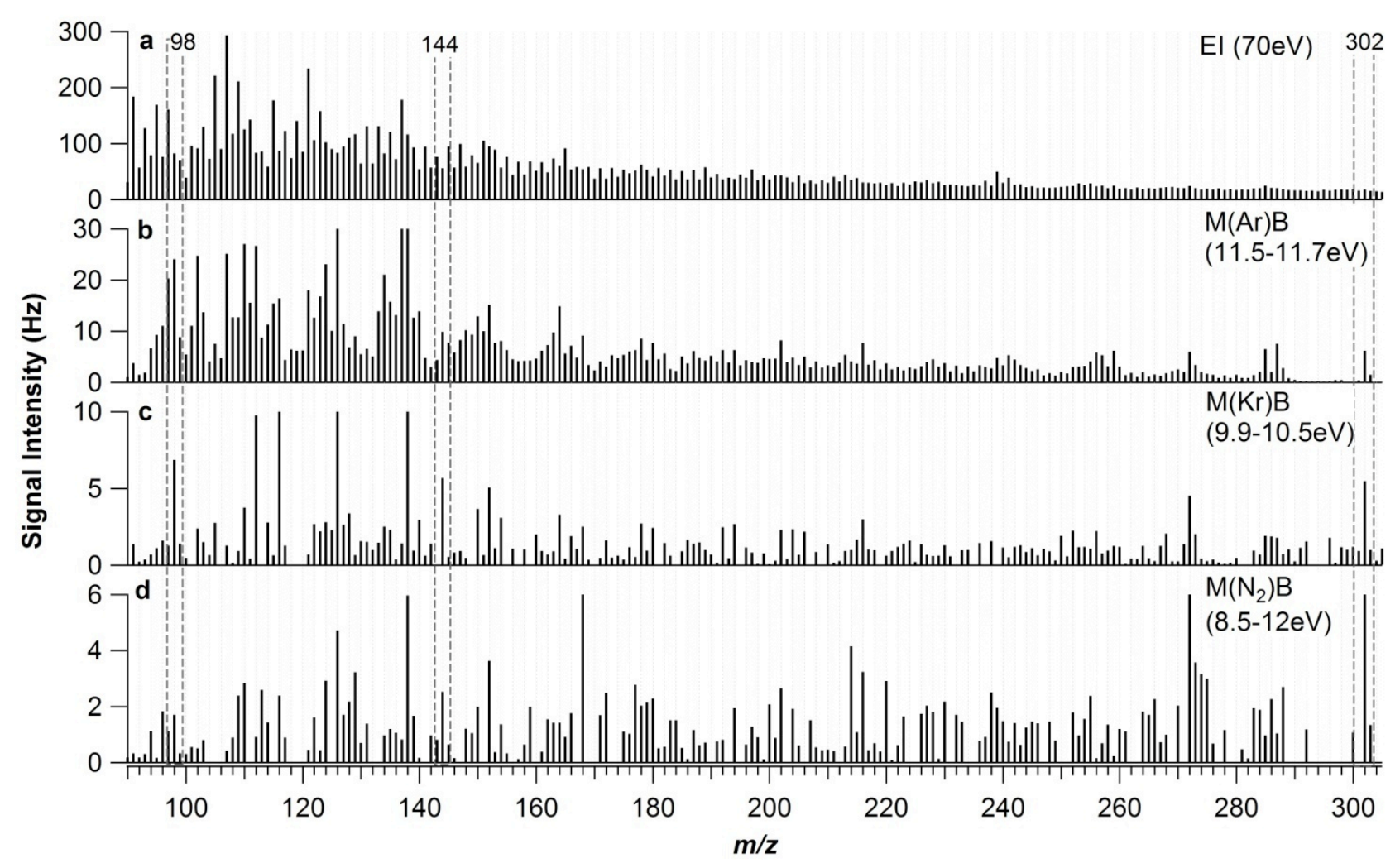

Figure 12. Same mass spectra shown in Figure S5, expanding in the range $m / z 50$ to 300 , to emphasize high $\mathrm{m} / \mathrm{z}$ ions. Marker ions consistent with those generated by the biomass burning molecular tracers levoglucosan $(\mathrm{m} / \mathrm{z}, 98$ and 144) and abietic acid $(\mathrm{m} / \mathrm{z}, 302)$ are highlighted. These peaks become more distinctly resolved in MAB, even though they may be present at higher intensity for EI, due to the reduced contribution of fragment ions at neighboring $\mathrm{m} / \mathrm{z}$.

\section{Conclusions}

A MAB ionization source has been coupled to an Aerodyne time-of-flight aerosol mass spectrometer. The source design allows real-time alternation between MAB and electron ionization. The discharge was demonstrated to be stable for several weeks, which is a requirement for extended field studies. Ionization with a discharge of $\mathrm{Ar}, \mathrm{Kr}$ or $\mathrm{N}_{2}$ generates less molecular fragmentation than similar analysis with EI, which could enable the detection of different components via factor analysis and thus potentially increase information about OA. 
$\mathrm{M}(\mathrm{Kr}) \mathrm{B}$ is the softest, while $\mathrm{M}(\mathrm{Ar}) \mathrm{B}$ ionization is the most sensitive of the three gases, producing total ion signal that is $0.1 \%$ of that achieved with EI. This relative sensitivity is lower than that reported for previous implementations of MAB ionization, but is consistent with the metastable flux recorded for the MAB-AMS discharge. Future work will focus on improving the intensity of the discharge and the transmission of the metastable beam into the ionization volume of the mass spectrometer, so that application to ambient OA becomes practical. Based on published characterization of other metastable beam sources, it is believed that up to a factor of 30 improvement in signal intensity could be achieved.

\section{Acknowledgements}

This research was funded by a Seed Grant from the University of Colorado-Boulder, NOAA OGP grant NA08OAR4310565, CARB CalNex funding, EPA STAR grant R833747, and NSF grants ATM-0449815 and ATM-0919189. CBR is grateful for NASA ESSF Graduate Fellowship (NNX09AO29H). We thank James Whitby (Tofwerk) and Claude Beaugrand (Abionix) for useful discussions, members of the Jimenez Group for technical support, Taehyoung Lee, Jeff L. Collett, and Sonia M. Kreidenweis from Colorado State University for the use of their data for MAB-EI comparisons, and Kip Carrico of CSU, and Emily Lincoln, Cycle Wold, and Wei-Min Hao of the Fire Lab staff for the organization of the FLAME-3 campaign. 


\section{CHAPTER III}

\section{METASTABLE ATOM SOURCE DESIGNS, OPERATION, AND MAINTENANCE}

Multiple MAB sources were designed, constructed, and tested to determine which had the highest metastable flux, was most stable, and could easily be turned on and off, so that the most reliable and efficient source design would be used during field campaigns. Within each design multiple degrees of freedom were also tested. For each design and all experiments, pure oleic acid standard aerosols were created using a TSI atomizer as described in the Experimental Methods of Chapter II.

\section{Faraday Cup Metastable Flux Detector}

Each source design was compared to the others using the Faraday cup, metastable flux detector briefly described in the Experiment Methods of Chapter II. Figure 13 shows a schematic of the flux detector. The metastable species flow into the detector just as they would to the ionization region of the TOFMS, and impact a stainless steel plate (shown in gray in figure 13) causing the release of an electron when there is a collision between the plate and the metastable species. As each metastable atom collides with the plate, not every collision produces an ejected electron; therefore a metastable-to-electron conversion factor $(\mathrm{X})$ of $0.13 \pm 0.09{ }^{42}$ when using $\mathrm{Ar}^{*}$ and $0.61 \pm 0.08{ }^{41}$ when using $\mathrm{He}^{*}$ is used. The ejected electron current is recorded with a picoammeter (pA) connected to the stainless steel plate and shown in figure 13. A bias voltage is applied to the outside walls of the detector to create an electric field attracting the ejected electrons so that they are not detected by the picoammeter. 


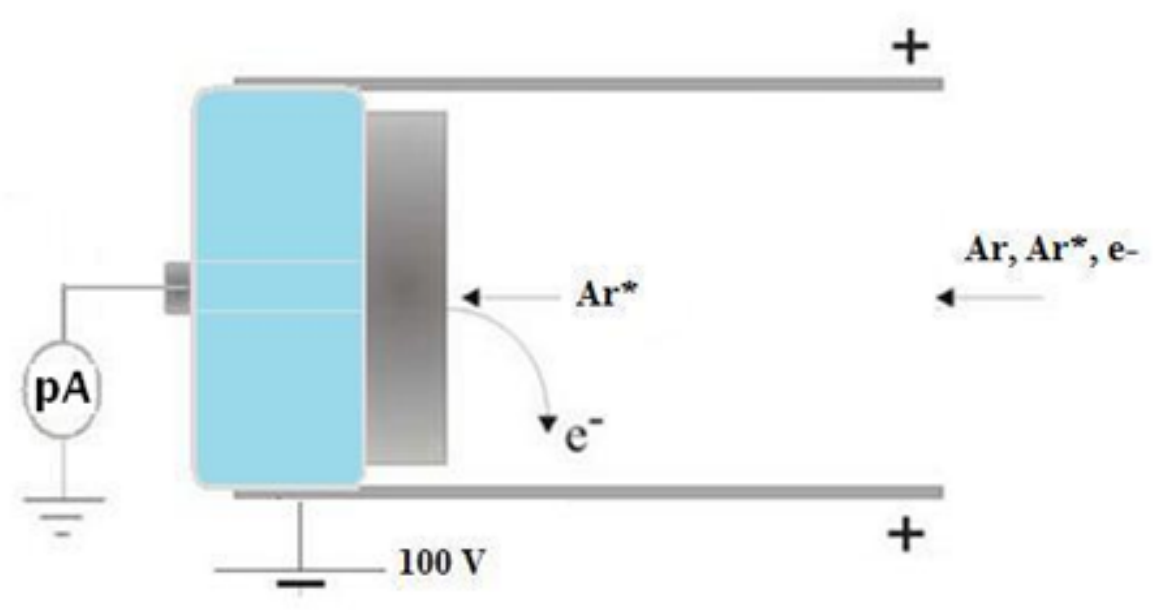

Figure 13. Schematic of the faraday cup metastable flux detector.

To determine whether or not the Faraday cup metastable flux detector was actually detecting and measuring the metastable current, a series of experiments were performed. First, the current was recorded while the bias voltage, magnet, and the deflection voltage were not applied. The resultant current oscillated around $-60 \mu \mathrm{A}$. The majority of the detected particles are electrons, leading to a large negative current. In the second experiment only the bias voltage was applied and the detected current was $-50 \mu \mathrm{A}$. The decrease in current may have resulted from the more efficient removal of the ejected electrons from the flux detector region, which were produced from the collision between the Ar* and the stainless steel plate. Or the decrease could have resulted from electrons created within the discharge not be reaching the detector and therefore not be detected. The third experiment applied the deflection voltage and the magnet without the bias voltage, in order to remove the electrons and reagent gas ions from the discharge beam and leave only the metastable atoms and the electrons ejected by the metastable atoms colliding with the plate. A $0.009 \mu \mathrm{A}$ current was observed. The current is now positive because the electrons from the discharge were removed by the magnetic field. The bias voltage was not applied; 
therefore the ejected electrons may have been detected by the picoammeter, resulting in a reduced current. Finally, both the bias voltage and deflection fields (including the magnet and deflection voltage) were applied resulting in a current of $0.015 \mu \mathrm{A}$. The current was positive because the electrons and other ions created within the discharge were removed via the bias voltage and the deflection fields through the processes just described.

To calculate the metastable flux the following equation is applied:

$$
\text { Metastable Flux }\left(\sec ^{-1} \mathrm{sr}^{-1}\right)=(\mathrm{I} / e) /(\alpha / \mathrm{X})
$$

where:

$$
\begin{aligned}
& \mathrm{I}=\text { electron current }(\mathrm{A}) \\
& e=\text { charge of an electron }(\mathrm{C}) \\
& \alpha=\text { solid angle }(\mathrm{sr}) \\
& \mathrm{X}=\text { metastable-to-electron conversion factor }
\end{aligned}
$$

A metastable-to-electron conversion factor (X) of $0.13 \pm 0.09{ }^{42}$ when using $\mathrm{Ar}^{*}$ and $0.61 \pm 0.08^{41}$ when using $\mathrm{He}^{*}$ is applied to the metastable flux calculation. The solid angle of each MAB source design is calculated by first determining the aperture that is limiting the metastable beam width within the design and then using the equation:

$$
\text { Solid Angle }(\mathrm{sr})=\pi *\left(\mathrm{r}^{2} / \mathrm{R}^{2}\right)
$$

where $\mathrm{r}$ is the radius of the limiting aperture and $\mathrm{R}$ is the distance from the discharge to the limiting aperture..$^{39}$

\section{Metastable Beam Source Designs}

Design 1 - Skimmer Anode Source. Metastable source design 1, shown in Figure 14, is based on the design of Fahey et al. ${ }^{28}$ and was used for all of the work in the paper submitted to 
Analytical Chemistry. The discharge in this design is maintained between a sharp cathode and a grounded stainless steel skimmer anode. The cathode is housed in a glass tube, referred to as the cathode chamber, with a nozzle at its exit. In order to optimize the source design, the skimmer dimensions, cathode material and style, and nozzle dimensions and material were all varied. The discharge gas and the discharge pressure were also varied. Table 1 lists the variables in each experiment performed.

Table I lists each experiment performed and the materials used with metastable source design 1. In experiment 1 , a brush cathode was used to create the discharge. All of the brush cathodes were made with pieces of $\sim 0.5 \mathrm{~mm}$ thick, $1 \mathrm{~cm}$ long wire. The discharge stayed lit for 30 minutes and would not relight after going out. Oxidized material was observed on the cathode after operation, likely causing the discharge failure. The brush cathode ${ }^{40}$ seemed to cause substantial sputtering of the discharge and holes were observed in the pulled glass nozzle. ${ }^{40}$ With holes in the nozzle, the discharge would not spark. Experiment 2 was not successful because the discharge would not spark. Experiment 3 used a pin cathode, which is one piece of $\sim 0.5 \mathrm{~mm}$ thick, $1 \mathrm{~cm}$ long wire. The same result was obtained in experiment 3 , in which the discharge would not spark. At the time of these experiments this lead to a belief that the platinum material for the cathode was the cause, but the discharge pressure was not varied which could be a major factor. Experiment 4 used a sharpened welding rod, with a $1 \mathrm{~mm}$ diameter and $\sim 2.5 \mathrm{~cm}$ long. The discharge stayed lit but the mass spectral signal level was low. Therefore in experiment 5 the discharge pressure was varied and it was discovered that pressures around 30 Torr gave a much higher signal. There are 2 aperture styles of boron nitride $(\mathrm{BN})$ nozzles $^{28}$ : one with a single diameter hole and one with a hole with 2 diameters (the expansion aperture style), as shown in Figure 15. The BN nozzle diameter and aperture style were changed in experiment 6. 
A higher signal level occurred with the smaller $350 \mu \mathrm{m}$ nozzle and the expansion style aperture. Experiment 7 utilized a stainless steel ring cathode ${ }^{40}$ with a diameter of $8.75 \mathrm{~mm}$ and thickness of $\sim 1 \mathrm{~mm}$. The discharge stayed lit and remained on for several hours. The nozzle material was varied in experiment 8 when the LAVA ${ }^{53}$ material (a commercially available ceramic) was used. The discharge would not stay lit for more than 30 minutes and would often not relight after the discharge went out. Experiments 9-11 used the same design configuration as experiment 5 and varied the discharge reagent gas. $\mathrm{Kr}$ and $\mathrm{N}_{2}$ gases both discharged, would stay lit, and would relight when the discharge was turned on and off. The He discharge would not stay lit for more than an hour at a time and would often not relight. It is likely that the purity of the He gas was too low to create a discharge. We observed with other gases that if the gas was not research grade or higher, this discharge would fail. Experiment 12, also like 5, used Ar gas and the discharge pressure was varied. A discharge pressure of 13 torr produced the most mass spectral signal for the parent peak of the standard aerosol used. The metastable flux achieved for design 1 using $\mathrm{Ar}^{*}$ is $3.6_{-1.5}^{+8.1} \times 10^{13} \mathrm{sr}^{-1} \mathrm{sec}^{-1}$, which is the largest flux achieved for any source design. Fahey et al. ${ }^{28}$ were able to achieve a flux using Ar* of $7.3 \times 10^{13} \mathrm{sr}^{-1} \mathrm{sec}^{-1}$. It may be possible to alter the Fahey source design to achieve a high flux, but the flux achieved with this design is very close to that achieved by Fahey. 


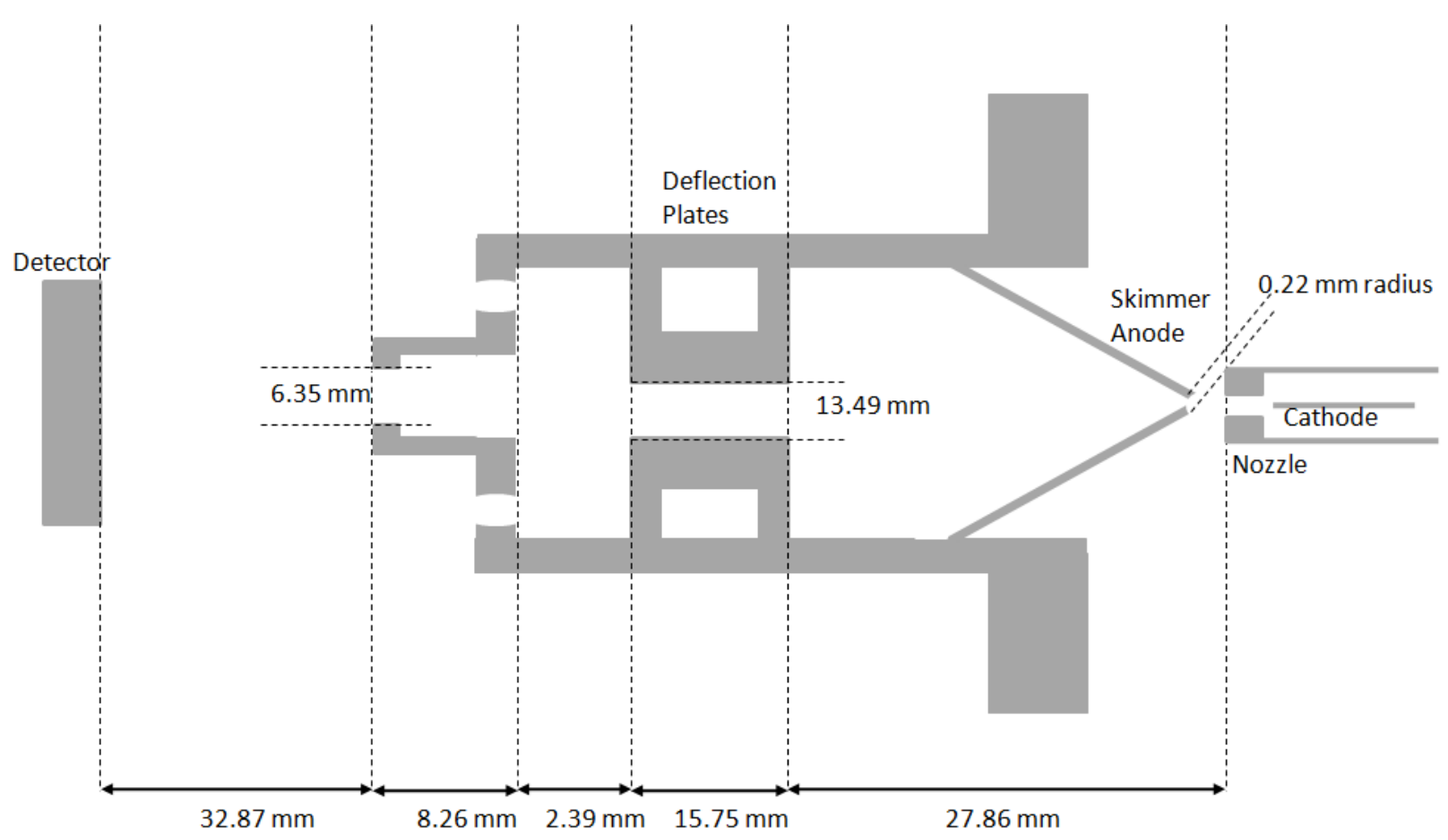

Figure 14. Schematic of Design 1 with design dimensions.
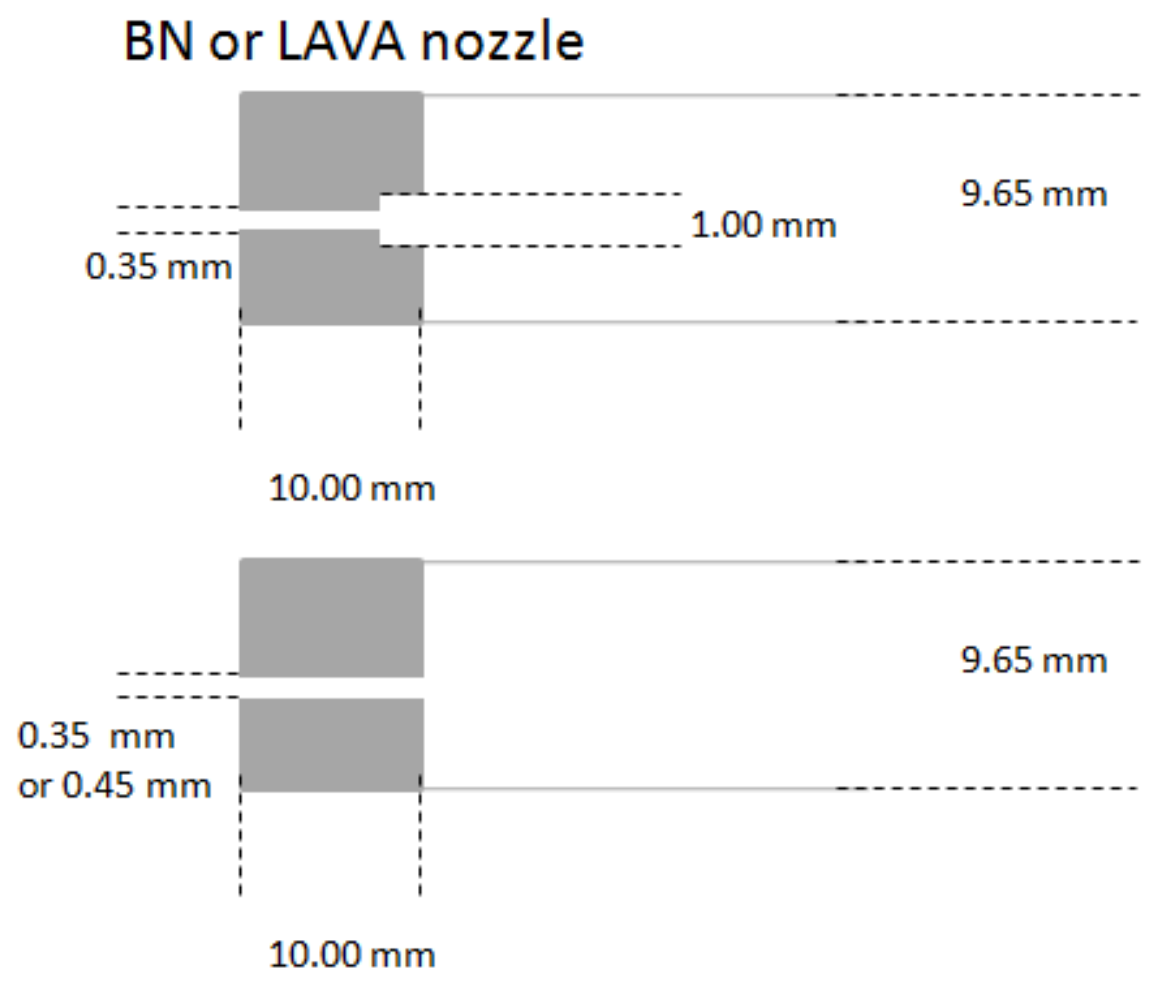
Figure 15. Schematic of the BN and LAVA nozzles

\begin{tabular}{|c|c|c|c|c|c|c|}
\hline Exp \# & $\begin{array}{c}\text { Discharge } \\
\text { Pressure } \\
\text { (torr) }\end{array}$ & $\begin{array}{l}\text { Cathode } \\
\text { Material }\end{array}$ & $\begin{array}{c}\text { Cathode } \\
\text { Style }\end{array}$ & $\begin{array}{c}\text { Nozzle Type } \\
\text { and } \\
\text { Dimensions }\end{array}$ & $\begin{array}{l}\text { Discharge } \\
\text { Gas }\end{array}$ & Results \\
\hline 1 & 300 & tantalum & $\begin{array}{l}\text { brush, } 2 \\
\text { wires }\end{array}$ & $\begin{array}{l}\text { pulled glass, } \\
350 \mu \mathrm{m} \\
\text { diameter }\end{array}$ & $\mathrm{Ar}$ & $\begin{array}{l}\text { Discharge went } \\
\text { out and would not } \\
\text { relight }\end{array}$ \\
\hline 2 & 200 & platinum & $\begin{array}{l}\text { brush, } 3 \\
\text { wires }\end{array}$ & $\begin{array}{l}\text { pulled glass, } \\
350 \mu \mathrm{m} \\
\text { diameter }\end{array}$ & $\mathrm{Ar}$ & $\begin{array}{l}\text { Would not } \\
\text { discharge }\end{array}$ \\
\hline 3 & 200 & platinum & pin & $\begin{array}{l}\text { pulled glass, } \\
350 \mu \mathrm{m} \\
\text { diameter }\end{array}$ & $\mathrm{Ar}$ & $\begin{array}{l}\text { Would not } \\
\text { discharge }\end{array}$ \\
\hline 4 & 100 & $\begin{array}{l}\text { thoriated } \\
\text { tungsten }\end{array}$ & $\begin{array}{l}\text { welding } \\
\text { rod, } 1 \mathrm{~mm} \\
\text { diameter }\end{array}$ & $\begin{array}{l}\mathrm{BN}, 350 \mu \mathrm{m} \\
\text { diameter }\end{array}$ & $\mathrm{Ar}$ & $\begin{array}{l}\text { Discharge would } \\
\text { stay lit, but low } \\
\text { mass spectrum } \\
\text { signal }\end{array}$ \\
\hline 5 & 30 & $\begin{array}{l}\text { thoriated } \\
\text { tungsten }\end{array}$ & $\begin{array}{l}\text { welding } \\
\text { rod, } 1 \mathrm{~mm} \\
\text { diameter }\end{array}$ & $\begin{array}{l}\mathrm{BN}, 1 \mathrm{~mm} \\
\text { entrance and } \\
350 \mu \mathrm{m} \text { exit } \\
\text { diameter }\end{array}$ & $\mathrm{Ar}$ & $\begin{array}{l}\text { Discharge would } \\
\text { stay lit, and had } \\
\text { high mass } \\
\text { spectrum signal }\end{array}$ \\
\hline 6 & 30 & $\begin{array}{l}\text { thoriated } \\
\text { tungsten }\end{array}$ & $\begin{array}{l}\text { welding } \\
\text { rod, } 1 \mathrm{~mm} \\
\text { diameter }\end{array}$ & $\begin{array}{l}\mathrm{BN}, 400 \mu \mathrm{m} \\
\text { diameter }\end{array}$ & $\mathrm{Ar}$ & $\begin{array}{l}\text { Discharge would } \\
\text { stay lit, but lower } \\
\text { mass spectrum } \\
\text { signal }\end{array}$ \\
\hline 7 & 30 & $\begin{array}{l}\text { stainless } \\
\text { steel }\end{array}$ & $\begin{array}{l}\text { ring, } \\
8.75 \mathrm{~mm} \\
\text { diameter }\end{array}$ & $\begin{array}{l}\mathrm{BN}, 1 \mathrm{~mm} \\
\text { entrance and } \\
350 \mu \mathrm{m} \text { exit } \\
\text { diameter }\end{array}$ & $\mathrm{Ar}$ & $\begin{array}{l}\text { Discharge would } \\
\text { stay lit, and had } \\
\text { comparable high } \\
\text { mass spectrum } \\
\text { signal }\end{array}$ \\
\hline 8 & 30 & $\begin{array}{l}\text { thoriated } \\
\text { tungsten }\end{array}$ & $\begin{array}{l}\text { welding } \\
\text { rod, } 1 \mathrm{~mm} \\
\text { diameter }\end{array}$ & $\begin{array}{l}\text { LAVA, } 1 \mathrm{~mm} \\
\text { entrance and } \\
350 \mu \mathrm{m} \text { exit } \\
\text { diameter }\end{array}$ & $\mathrm{Ar}$ & $\begin{array}{l}\text { Discharge went } \\
\text { out and would not } \\
\text { relight }\end{array}$ \\
\hline
\end{tabular}




\begin{tabular}{|l|l|l|l|l|l|l|}
\hline 9 & 20 & $\begin{array}{l}\text { thoriated } \\
\text { tungsten }\end{array}$ & $\begin{array}{l}\text { welding } \\
\text { rod, } 1 \mathrm{~mm} \\
\text { diameter }\end{array}$ & $\begin{array}{l}\text { BN, 1mm } \\
\text { entrance and } \\
350 \mu \mathrm{m} \text { exit } \\
\text { diameter }\end{array}$ & $\mathrm{Kr}$ & $\begin{array}{l}\text { Discharge would } \\
\text { stay lit, but } \mathrm{Kr} \\
\text { mass spectrum } \\
\text { signal less than Ar }\end{array}$ \\
\hline 10 & 20 & $\begin{array}{l}\text { thoriated } \\
\text { tungsten }\end{array}$ & $\begin{array}{l}\text { welding } \\
\text { rod, } 1 \mathrm{~mm} \\
\text { diameter }\end{array}$ & $\begin{array}{l}\mathrm{BN}, 1 \mathrm{~mm} \\
\text { entrance and } \\
350 \mu \mathrm{m} \text { exit } \\
\text { diameter }\end{array}$ & $\mathrm{He}$ & $\begin{array}{l}\text { Discharge went } \\
\text { out and would not } \\
\text { relight }\end{array}$ \\
\hline 11 & 20 & $\begin{array}{l}\text { thoriated } \\
\text { tungsten }\end{array}$ & $\begin{array}{l}\text { welding } \\
\text { rod, } 1 \mathrm{~mm} \\
\text { diameter }\end{array}$ & $\begin{array}{l}\text { BN, } 1 \mathrm{~mm} \\
\text { entrance and } \\
350 \mu \mathrm{m} \text { exit } \\
\text { diameter }\end{array}$ & $\mathrm{N}_{2}$ & $\begin{array}{l}\text { Discharge would } \\
\text { stay lit, but } \mathrm{N}_{2} \\
\text { mass spectrum } \\
\text { signal less than Ar }\end{array}$ \\
\hline 12 & 13 & $\begin{array}{l}\text { thoriated } \\
\text { tungsten }\end{array}$ & $\begin{array}{l}\text { welding } \\
\text { rod, } 1 \mathrm{~mm} \\
\text { diameter }\end{array}$ & $\begin{array}{l}\text { BN, 1mm } \\
\text { entrance and } \\
350 \mu \mathrm{m} \text { exit } \\
\text { diameter }\end{array}$ & Ar & $\begin{array}{l}\text { Discharge would } \\
\text { stay lit, and had } \\
\text { the highest mass } \\
\text { spectrum signal } \\
\text { level achieved }\end{array}$ \\
\hline
\end{tabular}

Table 1. Table of experiments performed with Design 1 while varying various parameters.

Design 2 - Off-Axis Anode Source. This design is based on that of Faubert et al. ${ }^{22,30}$ As shown in Figure 16, the skimmer was removed and a stainless steel plate was inserted off-axis to act as the anode. The cathode was made of copper. In this design, an off-axis discharge is created between 20-30 torr, which is thought to allow for only metastables flowing into the ionization region as the electrons and ions created in the discharge will already be removed because of the off-axis geometry. Both the LAVA and BN nozzle materials with a $1 \mathrm{~mm}$ entrance and $350 \mu \mathrm{m}$ exit diameter were tested. With either nozzle the discharge would light and go out after 30 minutes, after which the discharge would not relight. There were black burn marks within the MAB source indicating that the discharge was not striking between the anode and cathode but to the inside of the source, likely causing the unreliable discharge. Faubert et al. 
claim to achieve the largest metastable flux of $1.5 \times 10^{15}$ with He*. Because our source was not reliable, a metastable flux was never measured.

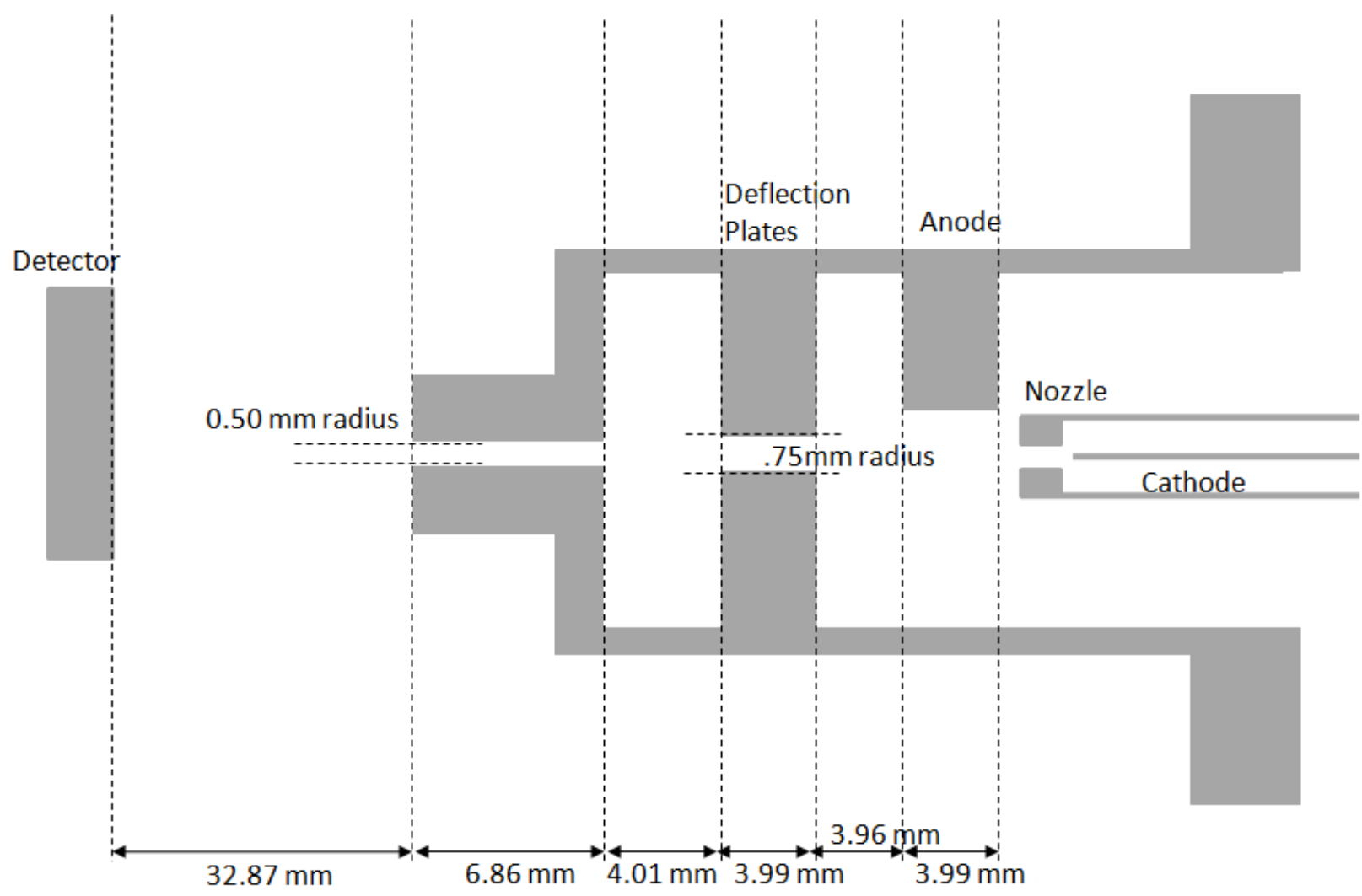

Figure 16. Schematic of Design 2 with design dimensions.

Design 3 - Stainless Steel Aperture Anode Source. Design 3 is very similar to design 1, but instead of a skimmer anode there is a stainless steel aperture serving as the anode as shown in Figure 17. This design is based on that of Dos Santos et al. ${ }^{46}$ The final parameters of Design 1, including reagent gas pressure, nozzle, and anode were implemented and 3 different radii apertures $(230,375$, and $750 \mu \mathrm{m})$ were tested. With the $230 \mu \mathrm{m}$ aperture anode, the discharge would only stay lit for 30 minutes and would not relight after it went out. The discharge with the 370 and $750 \mu \mathrm{m}$ apertures stayed lit for hours and would relight when one turned the discharge 
was turned on and off. With the $230 \mu \mathrm{m}$ aperture anode a metastable flux of $2.3 \times 10^{11} \mathrm{sr}^{-1} \mathrm{sec}^{-1}$ was achieved with $\mathrm{He}^{*}$ and with the $750 \mu \mathrm{m}$ aperture anode a flux of $1.7 \times 10^{12} \mathrm{sr}^{-1} \mathrm{sec}^{-1}$ was achieved with Ar*. Dos Santos et al. ${ }^{46}$ reported a flux of $2.0 \times 10^{14} \mathrm{sr}^{-1} \mathrm{sec}^{-1}$ with $\mathrm{He}^{*}$. Comparing the fluxes using $\mathrm{He}^{*}$ our source design produced a metastable flux that is three orders of magnitude lower and this difference was not likely to be overcome with slight modifications to the design, thus this design was not considered further.

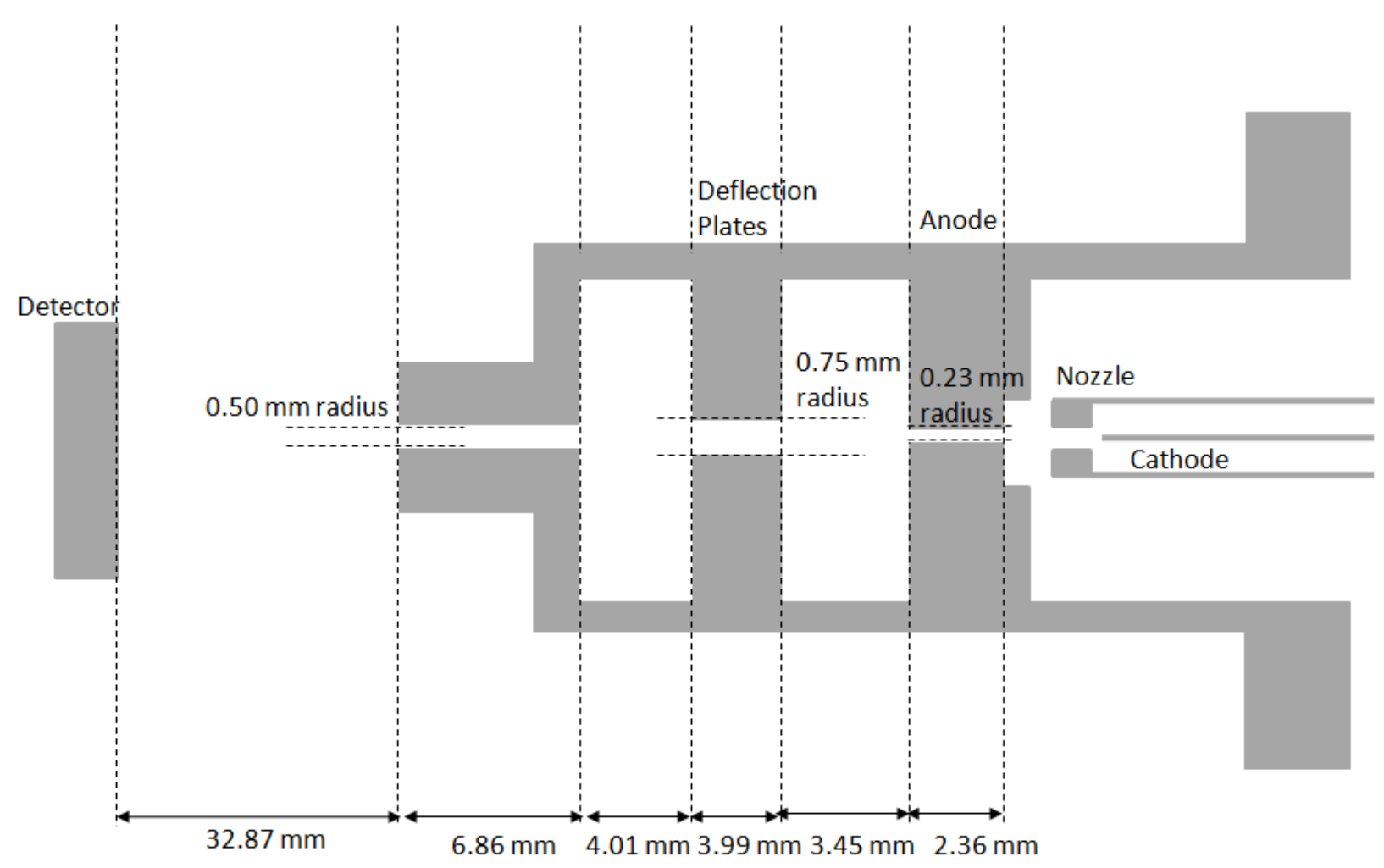

Figure 17. Schematic of Design 3 with design dimensions.

Design 4 - Microstructured Electrode Source. Design 4 is a based on DeKieviet et al. ${ }^{47}$ and is very different from the other source designs. The body of the source is the same as Design 3 , but there are two microstructured electrode copper disks, $150 \mu \mathrm{m}$ thick with a $1 \mathrm{~cm}$ diameter, 
separated only by a thin layer $(50 \mu \mathrm{m})$ of kapton foil. The center aperture of the electrodes is $200 \mu \mathrm{m}$. A copper stamp connected to the power supply is pressed against one electrode to transfer the voltage across the cathode so that a discharge is struck between the two electrodes, as shown in Figure 18. The discharge would light without problems and the discharge would stay lit for 12 hour periods. Whenever the discharge was switched on and off, it would light without problems. Despite the promising performance, no current was ever measured by the flux detector. It is likely that the discharge products were not reaching the ionization region because they were trapped near the electrodes and were likely being pumped away by the turbo pump connected to the MAB source.

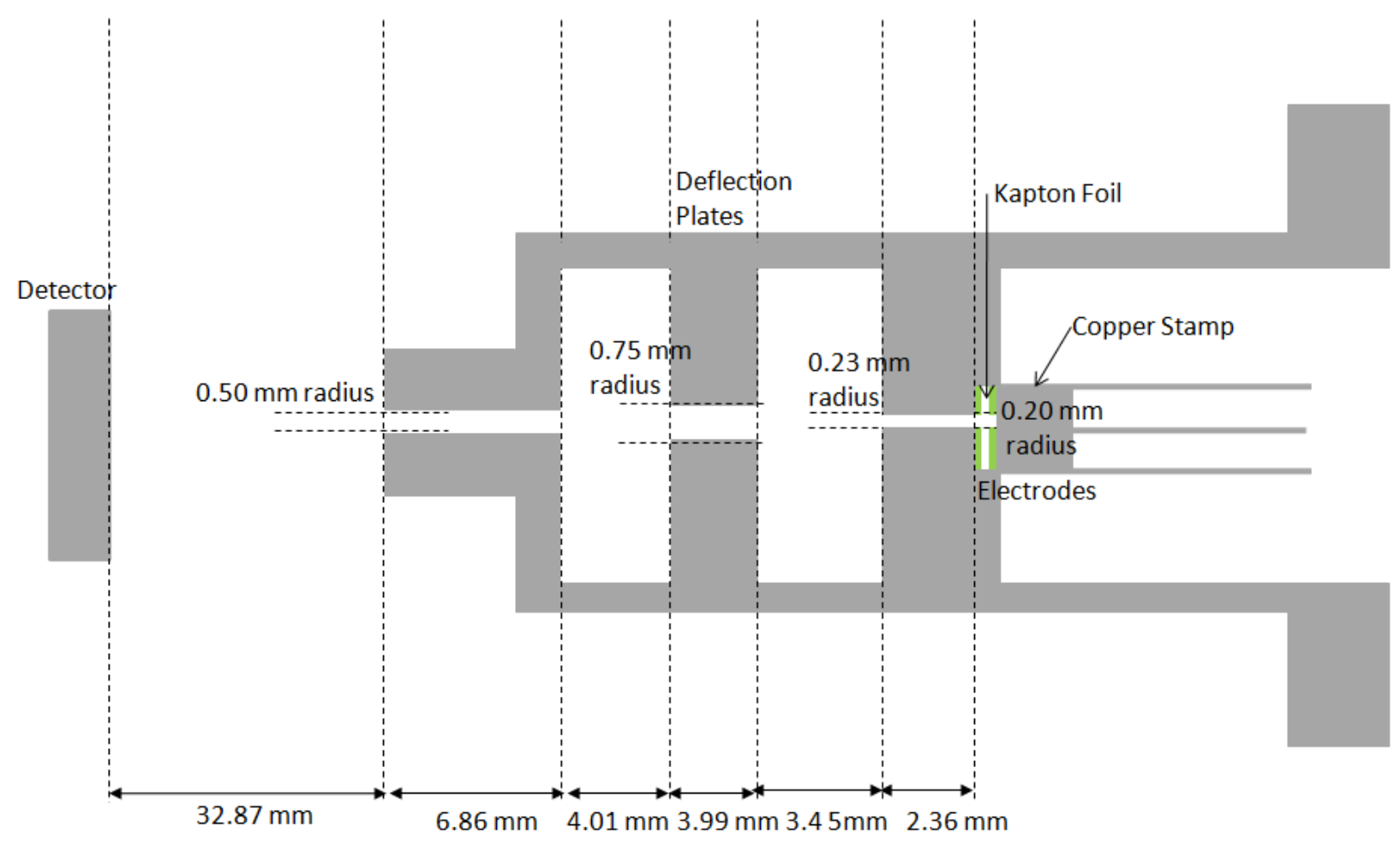

Figure 18. Schematic of Design 4 with design dimensions. 
Table 2 describes the abilities of each source design, as well as the flux achieved in this work and the primary reference and reported flux.

\begin{tabular}{|c|c|c|c|}
\hline Source Design \# & $\begin{array}{l}\text { Principal Reference } \\
\text { and Metastable Flux }\end{array}$ & Achieved Flux & Stability \\
\hline Design 1 & $\begin{array}{l}\text { Fahey et al. } \\
7.2 \times 10^{13} \mathrm{sec}^{-1} \mathrm{sr}^{-1} \\
\text { Ar discharge }\end{array}$ & $\begin{array}{l}3.6 \times 10^{13} \mathrm{sec}^{-1} \mathrm{sr}^{-1} \\
\text { Ar discharge }\end{array}$ & $\begin{array}{l}\text { Ability to run for } 3 \\
\text { weeks and can be } \\
\text { turned on and off }\end{array}$ \\
\hline Design 2 & $\begin{array}{l}\text { Faubert et al. } \\
1.5 \times 10^{-1} \mathrm{sec}^{-1} \mathrm{sr}^{-} \\
\text {He discharge }\end{array}$ & $\begin{array}{l}\text { No flux } \\
\text { measurement }\end{array}$ & $\begin{array}{l}\text { Cannot run for days } \\
\text { consistently, but } \\
\text { ability to be turned on } \\
\text { and off, but }\end{array}$ \\
\hline Design 3 & $\begin{array}{l}\text { Dos Santos et al. } \\
2 \times 10^{-1} \mathrm{sec}^{-1} \mathrm{sr}^{-} \\
\text {He discharge }\end{array}$ & $\begin{array}{l}2.3 \times 10^{11} \mathrm{sec}^{-1} \mathrm{sr}^{-1} \\
\text { He discharge } \\
1.7 \times 10^{-1} \mathrm{sec}^{-1} \mathrm{sr}^{-1} \\
\text { Ar discharge }\end{array}$ & $\begin{array}{l}\text { Ability to run } \\
\text { consistently for more } \\
\text { than a day and can be } \\
\text { turned on and off }\end{array}$ \\
\hline Design 4 & $\begin{array}{l}\text { DeKieviet et al. } \\
1 \times 14 \mathrm{sec}^{-1} \mathrm{sr}^{-1} \\
\text { He discharge }\end{array}$ & No flux achieved & $\begin{array}{l}\text { Ability to run for } \\
\text { days and can be } \\
\text { turned on and off }\end{array}$ \\
\hline
\end{tabular}

Table 2. Summary of the source designs and their achieved metastable fluxes.

\section{Metastable Source Operation}

The following is the procedure to operate the MAB source with the Aerodyne HR-ToF-AMS:

1) Check to make sure all 7 of the pumps are on and running at normal currents and at $100 \%$ full speed: 
The nominal pump currents before discharge and with the valve open to the reagent gas line with no gas flowing (ie. the needle valve is closed) are listed below. These "normal" values vary by $\pm 0.10 \mathrm{~A}$.

\begin{tabular}{|l|l|}
\hline Pump Name & Current (A) \\
\hline 2 & 1.30 \\
\hline 3 & 0.40 \\
\hline 4 & 0.30 \\
\hline 5 & 0.35 \\
\hline 6 & 0.30 \\
\hline MAB 301 & 1.40 \\
\hline MAB Turbo & 0.70 \\
\hline
\end{tabular}

2) Start reagent gas flow and open the needle valve so that the pressure reading on the MAB gas flow lines is around 15 Torr. The discharge pressure will be run around 13 Torr, but to discharge the pressure needs to be at 15 Torr.

3) Use a current-controlled high voltage power supply, to create the discharge. The one used in these experiments is in negative polarity mode and has a maximum voltage of $5000 \mathrm{~V}$. Set the power supply to the maximum voltage and set the current to $12 \mathrm{~mA}$. Turn on the power supply and press the button to apply the voltage. Since the power supply is current limiting, the $5000 \mathrm{~V}$ will decrease to between $700-1000 \mathrm{~V}$ to maintain the $12 \mathrm{~mA}$ current. After the discharge is struck, close the reagent gas pressure needle valve until the pressure gauge reads 13 Torr. 
4) The ToF Power Supply (TPS) voltages can now be turned on. The discharge can be struck with the TPS voltages on, but it is typically struck before turning the TPS on.

5) With the AMS running and with standard atomized particles coming in, the nozzle position can be adjusted with the floating flange to optimize the position of the nozzle (i.e., the position which gives the largest parent peak signal). However, this position is not as critical as was first thought. For the current source design 1, the position does not have a significant affect the signal intensity as long as the position is close to the center of the skimmer. The position can be adjusted and if the nozzle is off of the center of the skimmer the mass spectral signal will be significantly lower.

\section{Metastable Source Maintenance}

The following steps are to be taken when there is a problem with the discharge or during regular maintenance:

- Make sure to have a clean thoriated tungsten welding rod. Look for discoloration and oxidation. To clean, use sand paper to remove the oxidation and then clean with isopropyl alcohol, or the entire cathode can be replaced.

- Make sure that the o-ring in the BN nozzle is not cracked. If the o-ring is damaged it needs to be replaced because the pressure drop created with the nozzle would not be as substantial. To replace the o-ring use tweezers to remove the cracked o-ring and replace with a new o-ring.

- Make sure that the BN nozzle is not clogged. To clean it, use a small drill bit that is a bit smaller than the nozzle diameter to clean out. 
- Make sure that the skimmer is clean. Every time the MAB source is opened the skimmer should be cleaned with a Kimwipe and isopropyl alcohol.

- If the discharge goes out or will not light, it is most likely due to a dirty skimmer, clogged nozzle, and/or a dirty cathode.

- When putting the glass cathode chamber into the set up, push all the way forward until it hits the skimmer and then pull back the smallest amount possible. 


\section{CHAPTER IV}

\section{FUTURE RESEARCH}

New soft ionization sources for mass spectrometry are promising, and continue to be an exciting and actively pursued area of research in the mass spectrometry community. For the MAB soft ionization source, the next step is to optimize the design to achieve a higher metastable flux with the goal increased mass spectral sensitivity. A larger flux could be obtained by creating a design without deflection plates that allows for the discharge to be as close to the ionization region as possible. This new design should allow for a larger solid angle and therefore an increased metastable flux. 


\section{References}

1. Forster, P., Ramaswamy, V., Artaxo, P., Berntsen, T., Betts R., et al., Fourth Assessment Report of the Intergovernmental Panel on Climate Change, Cambridge University Press:

Cambridge, United Kingdom and New York, NY, USA, 2007.

2. Hallquist, M.; Wenger, J. C.; Baltensperger, U.; Rudich, Y.; Simpson, D., et al., Atmos.

Chem. Phys., 2009, 9, 5155-5236,

3. Chow, J. C.; Watson, J. G.; Pritchett, L. C.; Pierson, W. R.; Frazier, C. A., et al., Atmos. Environ., 1993, 27, 1185-1201,

4. Sullivan, A. P.; Weber, R. J.; Clements, A. L.; Turner, J. R.; Bae, M. S., et al., Geophys. Res. Lett., 2004, 31, L13105, 10.1029/2004g1019681.

5. Williams, B. J.; Goldstein, A. H.; Millet, D. B.; Holzinger, R.; Kreisberg, N. M., et al., J. Geophys. Res., 2007, 112, D10s26, 10.1029/2006jd007601.

6. Gilardoni, S.; Liu, S.; Takahama, S.; Russell, L. M.; Allan, J. D., et al., Atmos. Chem. Phys., 2009, 9, 5417-5432,

7. Decesari, S.; Mircea, M.; Cavalli, F.; Fuzzi, S.; Moretti, F., et al., Environ. Sci. Technol., 2007, 41, 2479-2484, 10.1021/es0617111.

8. Canagaratna, M. R.; Jayne, J. T.; Jimenez, J. L.; Allan, J. D.; Alfarra, M. R., et al., Mass Spectrom. Rev., 2007, 26, 185-222, 10.1002/mas.20115.

9. Oktem, B.; Tolocka, M. P.; Johnston, M. V., Anal. Chem., 2004, 76, 253-261, $10.1021 / \mathrm{ac} 0350559$.

10. Holzinger, R.; Williams, J.; Herrmann, F.; Lelieveld, J.; Donahue, N. M., et al., Atmos. Chem. Phys., 2010, 10, 2257-2267,

11. Thornberry, T.; Murphy, D. M.; Thomson, D. S.; de Gouw, J.; Warneke, C., et al., Aerosol Sci. Technol., 2009, 43, 486-501, 10.1080/02786820902763132.

12. Yatavelli, R. L. N.; Thornton, J. A., Aerosol Sci. Technol., 2010, 44, 61-74, $10.1080 / 02786820903380233$.

13. Hearn, J. D.; Smith, G. D., J. Phys. Chem. A, 2004, 108, 10019-10029, 10.1021/jp0404145.

14. LaFranchi, B. W.; Zahardis, J.; Petrucci, G. A., Rapid Commun. Mass Spectrom., 2004, $18,2517-2521,10.1002 / \mathrm{rcm} .1653$.

15. Ulbrich, I. M.; Canagaratna, M. R.; Zhang, Q.; Worsnop, D. R.; Jimenez, J. L., Atmos. Chem. Phys., 2009, 9, 2891-2918,

16. Northway, M. J.; Jayne, J. T.; Toohey, D. W.; Canagaratna, M. R.; Trimborn, A., et al., Aerosol Sci. Technol., 2007, 41, 828-839, 10.1080/02786820701496587.

17. Penning, F. M., Naturwissenschaften, 1927, 15, 818-818,

18. Setser, D. W., Acadenic Press, Inc.: New York City, 1979; 173-174

19. Anderson, D. R.; Bierbaum, V. M.; Depuy, C. H.; Grabowski, J. J., Int. J. Mass

Spectrom. Ion Processes, 1983, 52, 65-94,

20. Lofthus, A.; Krupenie, P. H., J. Phys. Chem. Ref. Data, 1977, 6, 113-307,

21. Ikonomou, M. G.; Rayne, S., Anal. Chem., 2002, 74, 5263-5272, 10.1021/ac020191j.

22. Faubert, D.; Paul, G. J. C.; Giroux, J.; Bertrand, M. J., Int. J. Mass Spectrom. Ion

Processes, 1993, 124, 69-77,

23. Reed, T. M., J. Phys. Chem., 1955, 59, 428-432,

24. Hiraoka, K.; Furuya, H.; Kambara, S.; Suzuki, S.; Hashimoto, Y., et al., Rapid Commun. Mass Spectrom., 2006, 20, 3213-3222, 10.1002/rcm.2706. 
25. Wu, Z. J.; Pu, J. X.; Li, L. M.; Fang, D. M.; Qi, H. Y., et al., J. Mass Spectrom., 2010, 45, 451-455, 10.1002/jms.1724.

26. Andrade, F. J.; Shelley, J. T.; Wetzel, W. C.; Webb, M. R.; Gamez, G., et al., Anal.

Chem., 2008, 80, 2646-2653, 10.1021/ac800156y.

27. Cody, R. B.; Laramee, J. A.; Durst, H. D., Anal. Chem., 2005, 77, 2297-2302, 10.1021/ac050152j.

28. Fahey, D. W.; Parks, W. F.; Schearer, L. D., J. Phys. E: Sci. Instrum., 1980, 13, 381-383,

29. Searcy, J. Q., Rev. Sci. Instrum., 1974, 45, 589-590,

30. Bertrand, M. J., Faubert, D., Peraldi, O., L'Heureux, A., (University of Montreal), Patent, U.S., 6124675, 2000.

31. Le Vot, C., Afonso, C., Beaugrand, C., Tabet, J.C., Int. J. Mass spectrom., 2010, In

Press,

32. Berkout, V. D., Anal. Chem., 2006, 78, 3055-3061, 10.1021/ac060069a.

33. Liu, P.; Ziemann, P. J.; Kittelson, D. B.; McMurry, P. H., Aerosol Sci. Technol., 1995, 22, 293-313,

34. Jayne, J. T.; Leard, D. C.; Zhang, X. F.; Davidovits, P.; Smith, K. A., et al., Aerosol Sci.

Technol., 2000, 33, 49-70,

35. Drewnick, F.; Hings, S. S.; DeCarlo, P.; Jayne, J. T.; Gonin, M., et al., Aerosol Sci.

Technol., 2005, 39, 637-658, 10.1080/02786820500182040.

36. DeCarlo, P. F.; Kimmel, J. R.; Trimborn, A.; Northway, M. J.; Jayne, J. T., et al., Anal.

Chem., 2006, 78, 8281-8289, 10.1021/ac061249n.

37. Baker, M.; Palmer, A. J.; Sang, R. T., Meas. Sci. Technol., 2003, 14, N5-N8,

38. Palmer, A. J.; Baker, M.; Sang, R. T., Rev. Sci. Instrum., 2004, 75, 5056-5058, 10.1063/1.1808059.

39. Traitler, N., Masters of Science, University of York, York, UK, 2002

40. Ashmore, J. P.; Sang, R. T., Meas. Sci. Technol., 2001, 12, N17-N21,

41. Dunning, F. B.; Rundel, R. D.; Stebbings, R. F., Rev. Sci. Instrum., 1975, 46, 697-701,

42. Schohl, S.; Klar, D.; Kraft, T.; Meijer, H. A. J.; Ruf, M. W., et al., Zeitschrift Fur Physik D-Atoms Molecules and Clusters, 1991, 21, 25-39,

43. McMeeking, G. R.; Kreidenweis, S. M.; Baker, S.; Carrico, C. M.; Chow, J. C., et al., J. Geophys. Res., 2009, 114, D19210, 10.1029/2009jd011836.

44. Kawanaka, J.; Hagiuda, M.; Shimizu, K.; Shimizu, F.; Takuma, H., Appl. Phys. B, 1993, $56,21-24$,

45. Leasure, E. L.; Mueller, C. R.; Ridley, T. Y., Rev. Sci. Instrum., 1975, 46, 635-637,

46. Dos Santos, F. P.; Perales, F.; Leonard, J.; Sinatra, A.; Wang, J., et al., European

Physical Journal-Applied Physics, 2001, 14, 69-76,

47. DeKieviet, M.; Durr, M.; Epp, S.; Lang, F.; Theis, M., Rev. Sci. Instrum., 2004, 75, 345$348,10.1063 / 1.1638869$.

48. Jimenez, J. L.; Canagaratna, M. R.; Donahue, N. M.; Prevot, A. S. H.; Zhang, Q., et al., Science, 2009, 326, 1525-1529, 10.1126/science.1180353.

49. Zhang, Q.; Jimenez, J. L.; Canagaratna, M. R.; Allan, J. D.; Coe, H., et al., Geophys. Res. Lett., 2007, 34, L13801, 10.1029/2007g1029979.

50. Huffman, J. A.; Docherty, K. S.; Aiken, A. C.; Cubison, M. J.; Ulbrich, I. M., et al., Atmos. Chem. Phys., 2009, 9, 7161-7182,

51. Aiken, A. C.; Salcedo, D.; Cubison, M. J.; Huffman, J. A.; DeCarlo, P. F., et al., Atmos . Chem. Phys., 2009, 9, 6633-6653, 
52. Lee, T., Sullivan, A.P., Mack, L., Jimenez, J.L., Kreidenweis, S.M., Onasch, T.B., Worsnop, D.R., Malm,W., Wold,C.E., Hao,W.M., and Collett,J.L. , Aerosol Sci. Technol., 2010, In Press,

53. Hwang, K. S.; Lee, M. J.; Yi, M. Y.; Lee, J. W., Thin Solid Films, 2009, 517, 3866-3869, 10.1016/j.tsf.2009.01.132. 